\title{
Combining Airborne Photographs and Spaceborne SAR Data to Monitor Temperate Glaciers: Potentials and Limits
}

\author{
Emmanuel Trouvé, Member, IEEE, Gabriel Vasile, Member, IEEE, Michel Gay, \\ Lionel Bombrun, Student Member, IEEE, Pierre Grussenmeyer, Tania Landes, Jean-Marie Nicolas, \\ Philippe Bolon, Member, IEEE, Ivan Petillot, Andreea Julea, Lionel Valet, \\ Jocelyn Chanussot, Senior Member, IEEE, and Mathieu Koehl
}

\begin{abstract}
Monitoring temperate glacier activity has become more and more necessary for economical and security reasons and as an indicator of the local effects of global climate change. Remote sensing data provide useful information on such complex geophysical objects, but they require specific processing techniques to cope with the difficult context of moving and changing features in high-relief areas. This paper presents the first results of a project involving four laboratories developing and combining specific methods to extract information from optical and synthetic aperture radar (SAR) data. Two different information sources are processed, namely: 1) airborne photography and 2) spaceborne C-band SAR interferometry. The difficulties and limitations of their processing in the context of Alpine glaciers are discussed and illustrated on two glaciers located in the Mont-Blanc area. The results obtained by aerial triangulation techniques provide digital terrain models with an accuracy that is better than $30 \mathrm{~cm}$,
\end{abstract}

Manuscript received July 5, 2006; revised November 15, 2006. This work was supported by the French Research Agency under the MEGATOR Project.

E. Trouvé and G. Vasile are with the Laboratoire d'Informatique, Systèmes, Traitement de l'Information et de la Connaissance, Université de Savoie, Polytech'Savoie, F.74944 Annecy-le-Vieux Cedex, France, and also with the Grenoble Image Parole Signal et Automatique Laboratory, Institut National Polytechnique de Grenoble, Centre National de la Recherche Scientifique, 38402 Saint-Martin-d'Hères, France (e-mail: emmanuel.trouve@ univ-savoie.fr; gabriel.vasile@univ-savoie.fr).

M. Gay, L. Bombrun, and J. Chanussot are with the Grenoble Image Parole Signal et Automatique Laboratory, Institut National Polytechnique de Grenoble, Centre National de la Recherche Scientifique, 38402 Saint-Martind'Hères, France (e-mail: michel.gay@lis.inpg.fr; lionel.bombrun@lis.inpg.fr; jocelyn.chanussot@lis.inpg.fr).

P. Grussenmeyer, T. Landes, and M. Koehl are with the Equipe Photogrammétrie et Géomatique, Modèles et Simulations Pour l'Architecture, l'Urbanisme et le Paysage-Photogrammetrie Architechturale et Geomatique UMR 694, Institut National des Sciences Appliquees de Strasbourg, 67084 Strasbourg, France (e-mail: pierre.grussenmeyer@insa-strasbourg.fr; tania. landes@insa-strasbourg.fr; mathieu.koehl@insa-strasbourg.fr).

J.-M. Nicolas is with the Département Traitement du Signal et des Images GET-Télécom Paris, Ecole Nationale Supérieure des Télécommunications, 75013 Paris, France (e-mail: nicolas@tsi.enst.fr).

P. Bolon, I. Petillot, and L. Valet are with the Laboratoire d'Informatique, Systèmes, Traitement de 1'Information et de la Connaissance, Université de Savoie, Polytech'Savoie, F.74944 Annecy-le-Vieux Cedex, France (e-mail: philippe.bolon@univ-savoie.fr; ivan.petillot@univ-savoie.fr; lionel.valet@ univ-savoie.fr).

A. Julea is with the Laboratoire d'Informatique, Systèmes, Traitement de l'Information et de la Connaissance, Université de Savoie, Polytech'Savoie, 74016 Annecy, France, and also with Space Sciences Institute, 76900 Bucharest, Romania (e-mail: andreea.julea@univ-savoie.fr).

Color versions of one or more of the figures in this paper are available online at http://ieeexplore.ieee.org.

Digital Object Identifier 10.1109/TGRS.2006.890554 which is compatible with the computation of volume balance and useful for precise georeferencing and slope measurement updating. The results obtained by SAR differential interferometry using European Remote Sensing Satellite images show that it is possible to measure temperate glacier surface velocity fields from October to April in one-day interferograms with approximately 20-m ground sampling. This allows to derive ice surface strain rate fields required to model the glacier flow. These different measurements are complementary to results obtained during the summer from satellite optical data and ground measurements that are available only in few accessible points.

Index Terms-Airborne photogrammetry, digital terrain model (DTM), synthetic aperture radar (InSAR) interferometry, temperate glacier, velocity field.

\section{INTRODUCTION}

I N RECENT decades, a spectacular retreat has been observed on most of the monitored Alpine glaciers [1], [2]. If this evolution is confirmed in the coming years, it will have some important consequences in terms of water resources, economical development, and risk management in the surrounding areas [3], [4]. Up to now, only $1 \%$ of the existing world temperate glaciers have been monitored [5], mostly by ground measurements, which often provide information only once or twice a year at a few points. Because of the difficulty of reaching high-altitude glaciers in risky mountainous areas, acquisition and processing of remotely sensed data should provide more information to improve glacier monitoring [4], [6]. Satellitebased glacier monitoring programs such as Global Land Ice Measurements from Space (http://www.glims.org) have started to build a database of glaciers around the world [7]. In the Alps, in high mountain areas where the glacier activity has to be monitored, a large series of airborne photographs and spaceborne synthetic aperture radar (SAR) images is often available through local environmental agencies [8] and space agencies. However, gathering multisource data sets for a given area and extracting the desired measurements (surface velocity fields, surface and bottom topography, etc.) remain difficult tasks.

This paper presents the first results of a project that involves four laboratories specializing in optical and SAR image processing, and data fusion techniques. A global strategy illustrated in Fig. 1 is proposed to extract from the large number of remotely sensed images information that is useful in monitoring 


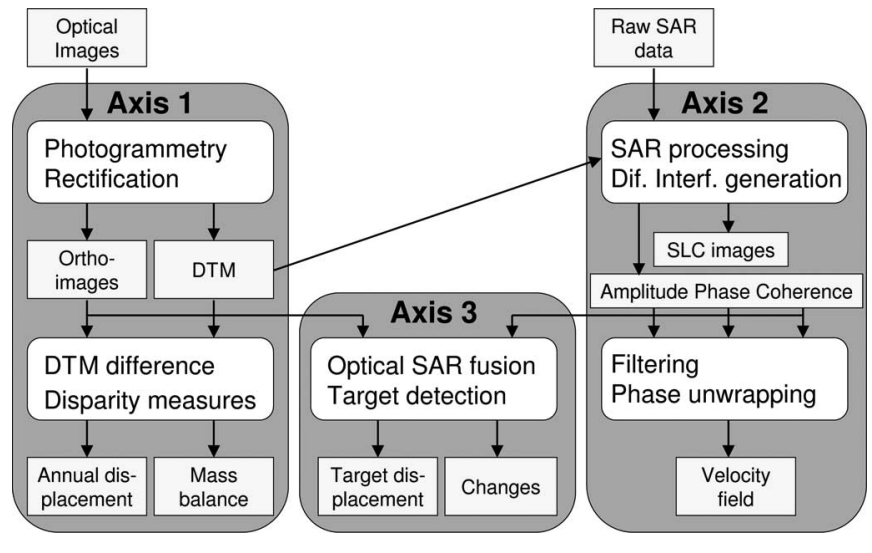

Fig. 1. Flowchart of the three main research axes proposed to extract information from optical and SAR data to monitor glacier activity; the main processing steps are in white, while the data are in yellow (light gray).

glacier evolution and evaluating the risk in the surrounding areas. The three main research axes are given as follows:

1) construction of digital terrain models (DTMs) and orthoimages from high-resolution optical images, and computation of differences after one or several years to detect changes such as volume variations, glacier retreat, lakes appearing/disappearing, etc.;

2) computation of differential C-band SAR interferograms by subtracting the topography provided by the previous results to obtain displacement fields over only a few days;

3) fusion of the feature detections and displacement measurements provided by the first two axes, in order to improve the confidence in the displacement/evolution measurements and to obtain higher level information such as change detection and risk maps.

In this paper, we focus on the first steps of the optical and SAR axes, which are given as follows:

- computation of DTMs by photogrammetry from airborne photographs;

- computation of velocity fields by SAR differential interferometry (D-InSAR) from satellite SAR images.

The principles of these two techniques are well established, but conventional processing is often difficult to apply in the context of Alpine glaciers.

In the field of photogrammetry, DTMs have been generated in similar studies dealing with monitoring high mountain terrain deformation. In [9], digital photogrammetry is applied to analyze changes in elevation and horizontal surface velocities. The goal of this paper was to determine surface topography and surface kinematics via high-altitude aerial photographs of two different years. Previously, Fox and Nuttall showed that photogrammetry can be used as a research tool by glaciologists [10]. Indeed, they produced photogrammetric compilations of two of the glaciers under study using 1990 aerial photographs. They examined the results and difficulties encountered in assessing the accuracy of the photogrammetric data. Photogrammetry was regarded primarily as a source of DTMs rather than as a cartographic tool. The derived digital model proved its efficiency for glaciological analysis [9], [11].
In the field of SAR interferometry, different approaches have been applied for studying glacier dynamics. The repeat-pass SAR acquisitions of the European Remote Sensing (ERS)-1/2 tandem mission provided a large database for glacier monitoring. One of the approaches used to study small movements over large areas is D-InSAR, which consists in differencing either two SAR interferograms or one interferogram and a topographical interferogram simulated by using a DTM over the same target area [12], [13]. In [14], nine ERS-1/2 tandem interferograms with useful scene coherence have been reported for measuring the surface flow of the Saskatchewan alpine glacier in the Canadian Rocky Mountains. With a mean velocity of about $15 \mathrm{~cm} /$ day, the obtained results agreed with the mean from surveying techniques. In addition, by using one interferogram formed by two acquisitions of the ERS-1 satellite at three-day intervals, the motion of the Black Rapids Glacier (AK) was assessed in [15]. The obtained accuracy was in the range of $5 \%-10 \%$ with a mean annual velocity of about $13 \mathrm{~cm} /$ day. Other geophysical properties can be extracted directly from the InSAR wrapped phase. In [16], the longitudinal strain rates of the Recovery Glacier (east Antarctica) have been estimated from RADARSAT-1 interferograms. Comparisons with the available ground data revealed a strain rate error of $17 \%$, corresponding to a tensile strength error of $5.3 \%$.

Although the D-InSAR processing chain is built from standard well-established InSAR algorithms as coregistration of interferograms, phase subtraction, and phase unwrapping, this procedure is often error prone because of complex glacier topography, phase noise at glacier boundaries, or atmospheric heterogeneities [17]. As the phase-unwrapping algorithm is the most sophisticated procedure in interferometric signal processing, a gradient approach (GINSAR) has been proposed by Sharov et al. [18] for differential processing of repeat-pass SAR interferograms in the context of glacier change detection and motion estimation. It has been validated on several tidewater glaciers from the Arctic regions. In order to separate ground displacement from atmospheric perturbations, a different approach based on the concept of permanent scatterers (PS) has been proposed [19] and successfully applied in urban areas. In the glacier areas where exposed rocks are visible, various backscatterers with a constant signature can be considered as potential PS, but results using this approach have not been reported. Beside the use of interferometric phase, a different approach based on intensity images has been proposed to measure displacement [20], [21]. In [22], the surface displacements are measured by correlating and tracking the image speckle pattern between two repeat-pass SAR acquisitions (speckle tracking). The advantages of the speckle tracking approach are less sensitivity to decorrelation and lack of need for the phaseunwrapping procedure [23]. However, the local amplitude variations (texture) should be high enough and the two speckle realizations should be quite dependent within the interferometric SAR image pair to ensure high correlation values.

Most of the published results are based on conventional SAR interferometry and obtained on glaciers located near polar regions [24], [25]. Fewer InSAR results have been published on temperate glaciers [14], [26], and up to now, only communications have reported results over Alpine glaciers [27], [28]. 
The context of temperate glaciers, especially with the climate in the Alps, is rather different from the context of polar and high-latitude glaciers.

- High-relief topography reduces the visibility of valley glaciers. They are rarely visible in both ascending and descending passes. When only one projection of the displacement on the SAR line of sight (LOS) is available, deriving 3-D velocity fields requires a stronger hypothesis (the flow direction) than when two projections are available [24]. Moreover, even when two projections are available, the high latitude increases the angle between ascending and descending tracks. Angles close to $90^{\circ}$ are more suitable than the approximately $20^{\circ}$ angle at the Alps' latitude.

- The small size of Alpine glaciers (typically about $10 \mathrm{~km}$ long and often just 1 or $2 \mathrm{~km}$ wide) has two main consequences for the processing: It reduces the size of possible filtering of the interferograms and the DTM, and increases the phase-unwrapping difficulty when glaciers are separated in several disconnected parts.

- The ice temperature of the low-altitude glaciers is very close to zero from the bedrock up to the surface. This strongly reduces the penetration length of electromagnetic waves [29]. The measurement of the ice-thickness distribution by low-frequency ground-penetrating radar or airborne ice-sounding radar is more difficult. This distribution is required to use the principle of mass conservation to convert InSAR velocity measurements to 3-D velocities as successfully performed over the Storströmmen glacier in northeast Greenland [30], [31].

Such differences have an impact on D-InSAR measurement feasibility, complementary data availability, and the processing chain: Different steps and hypotheses are strongly context dependent.

In order to apply photogrammetry and SAR interferometry in the context of Alpine glaciers, their potential and limitations have to be carefully investigated. The objective of this paper is to perform such investigations for airborne optical images and SAR D-InSAR using ERS C-band images. Airborne photography allows the computation of high-resolution DTMs on the glacier surface and the surrounding moraines, whereas spaceborne SAR interferometry provides the projection of the surface velocity field in the SAR LOS. The DTM information is necessary for the D-InSAR processing to remove topographic fringes, resample the results in ground geometry, and reconstruct the three components of the displacement vectors. Since the studied glaciers are visible only in descending passes, the three components are obtained using the surface-parallel flow (SPF) assumption and the maximum slope direction [15]. The result should be considered as "quasi-3-D" velocity vectors since pure velocity and ablation/accumulation effects are merged. The different steps of the processing chains and seasonal limitations are carefully analyzed with a series of ERS tandem interferograms over Alpine glaciers located in the Mont-Blanc area.

The remainder of this paper is organized as follows. The test site and the data set collected over the Mer de Glace and Argentière glaciers are presented in Section II. The processing

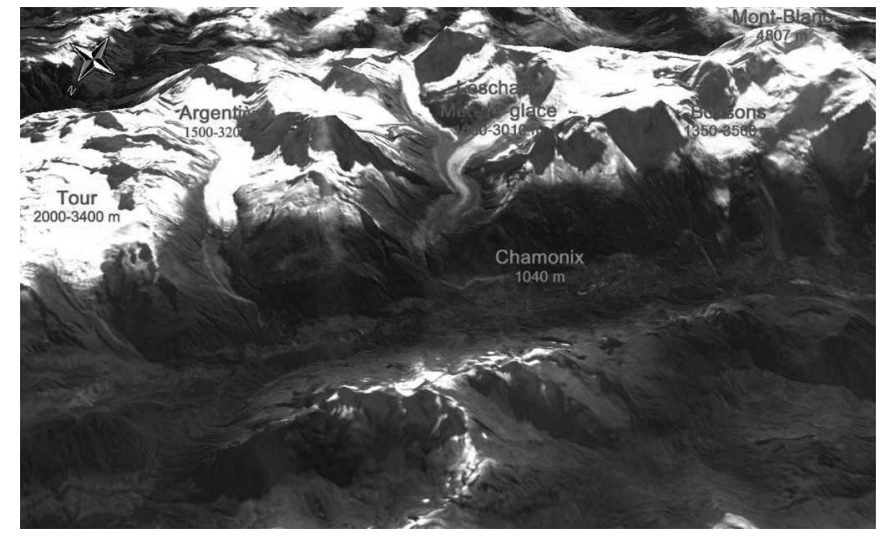

Fig. 2. Chamonix-Mont-Blanc test site. Main glaciers and geographical features. Shown is the 3-D model draped with a SPOT-2 multispectral image during the summer of 2000.

of optical airborne images and high-resolution DTM obtained over Mer de Glace glacier are described in Section III. The different steps of the D-InSAR processing chain are presented and analyzed in Section IV. Section V presents the displacement field derived from the previous results and the comparisons with ground measurements.

\section{Test ARea AND Data Sets}

The project test site is located in the Alps, near the borders between France, Italy, and Switzerland. It goes from the glacier of Le Grand Plateau ( $\left.45^{\circ} 50^{\prime} \mathrm{N}, 6^{\circ} 51^{\prime} \mathrm{E}\right)$ about $4000 \mathrm{~m}$ above sea level (ASL) up to the Trient glacier $\left(46^{\circ} 59^{\prime} \mathrm{N}, 7^{\circ} 01^{\prime} \mathrm{E}\right)$ about $2000 \mathrm{~m}$ ASL. It includes the Mont-Blanc $(4810 \mathrm{~m})$, the Chamonix valley $(1000 \mathrm{~m})$, and two well-known and instrumented glaciers, i.e., Mer de Glace and Argentière (Fig. 2).

This test site is suitable for investigating the potential of remotely sensed data to monitor glacier activity for several reasons, such as the following:

- geophysical diversity of glaciers: a large range of altitudes (1000-4800 m) and glacial velocities $(0-30 \mathrm{~cm} /$ day over Mer de Glace and Argentière glaciers, and up to $3 \mathrm{~m} /$ day in the Géant icefall [32]), complex surface cover (mixture of snow, ice, and rocks), and the presence of water-collecting tunnels (Argentière), which enable subglacial point velocity measurements [33];

- data availability: the existence of various data sets from spaceborne or airborne sensors, which are acquired with different time intervals in different seasons, and ground measurements, which help in the data processing, information fusion, and validation of the final results [34].

\section{A. Optical Data}

For several decades, airborne photography has been an important source of information over a large number of glaciers in the Alps [8], [35]. In the French part, the main glaciers of three different regions have been covered by airborne photography every three years between 1975 and 1995 (Table I). More recent campaigns $(1998,2000$, and 2004) have been performed over the whole "Haute-Savoie" $\left(4598 \mathrm{~km}^{2}\right)$, where the studied glaciers are located [8]. The advantage of such data is the high 
TABLE I

AIRBorne PHOTOGRAPHY CAMPAIGNS OVER THREE DIFFERENT Glacier REgiOnS IN THE French Alps ("X" DenOtes EXISTENCE of a Campaign That Year). The Mont-Blanc Region Has Also BEEN COVERED IN 1998, 2000, AND 2004 By CAMPAIGNS Performed Over the Whole "Haute Savoie"

\begin{tabular}{|l||c|c|c|c|c|c|c|c|}
\hline & 1975 & 1976 & 1978 & 1979 & 1981 & 1982 & 1983 & 1984 \\
\hline Mont-Blanc & & $\times$ & & $\times$ & & $\times$ & & \\
\hline Savoie & $\times$ & & $\times$ & & $\times$ & & $\times$ & \\
\hline Oisans & $\times$ & & $\times$ & & $\times$ & & & $\times$ \\
\hline \hline & 1985 & 1986 & 1988 & 1989 & 1990 & 1991 & 1992 & 1995 \\
\hline Mont-Blanc & $\times$ & & & & $\times$ & & & $\times$ \\
\hline Savoie & & $\times$ & & $\times$ & & & $\times$ & \\
\hline Oisans & & & $\times$ & & & $\times$ & & \\
\hline
\end{tabular}

resolution of digitized photos or digital image acquisitions. They allow the computation of high-resolution DTMs and orthoimages with accurate positioning obtained by using a few GPS control points (see Section III). Another advantage is the ability to reconstruct past glacier configurations. Indeed, data from 1990 and 1995 are available and will be of particular interest for interpretations over the last decades. However, the main disadvantage is the high cost of each campaign, which usually covers only a few glaciers, making such data rarely available for the scientific community.

Spaceborne optical images with their increasing resolution are a potential alternative. A detailed map of the summer ice velocity field for our study area has been obtained previously by cross-correlating SPOT5 optical images [36]. One of the advantages of such data is that a single image can cover the whole group of glaciers of a mountain area. Moreover, alongtrack stereo-pair acquisition capability and multispectral sensors allow satellites such as the Advanced Spaceborne Thermal Emission and Reflection Radiometer (ASTER) to contribute to ice measurements by providing both elevation models and surface classification based on spectral signature [7]. This information can be used to identify specific features (e.g., emerging lakes, ice cracks, glacier tongues) for change detection and risk assessment. Hybrid DTMs produced by the merging of optical and SAR DTMs also seem to be promising [4], [6].

Nevertheless, the spatial resolution of these images compared to that of aerial photography remains a disadvantage. The achievable accuracy for elevation changes and horizontal displacements approximates the spatial resolution, i.e., $15 \mathrm{~m}$ for ASTER against less than $0.30 \mathrm{~m}$ for aerial photography [9]. In [9], a photogrammetrically derived DTM was compared with an ASTER DTM. The latter one provided an accuracy between $\pm 18 \mathrm{~m} \mathrm{rms}$ (in moderately mountainous terrain) and $\pm 60 \mathrm{~m} \mathrm{rms}$ (in rough high mountain topography). Thus, ASTER and SPOT image pairs provide DTMs but with a DTM accuracy not comparable to that reached by photogrammetric techniques. Satellite DTM can be used to derive elevation changes if the time separation is a few years [37]. The aerial DTM high accuracy should allow to compute annual elevation changes that are useful in deriving annual mass balance. Moreover, because of the weather conditions on mountainous areas and orbital constraints, existing data with a meter-scale resolution are still rare, and programmed acquisition of stereoscopic pairs remains uncertain.

\section{B. SAR Data}

Satellite SAR images are more and more used to observe glaciers particularly because of two great advantages: 1) The active SAR sensor acquires images regardless of weather conditions. 2) It measures both the amplitude and phase of the backscattered signal. With the resolution of the data that have been available up to now (about $20 \mathrm{~m}$ with ERS images), the amplitude is often difficult to use in extracting precise information on specific features. The next generation of SAR satellites should provide meter-resolution images and fully polarimetric data, which will be useful to detect different features and backscattering mechanisms [38]. With interferometric data, the geometric deterministic component of the phase offers the opportunity to measure the glacier displacement between the two acquisitions with a precision of a fraction of the wavelength $(5.6 \mathrm{~cm}$ in C-band). The two main limitations of this technique are the temporal decorrelation of the signal over glaciers (see Section IV-B2) and the need to separate the topographical fringes from the displacement fringes. Among the different techniques that can be used [18], the safest one consists in using a DTM and the radar geometry to simulate the phase signal due to the topography and to compute the difference with the real interferogram.

In this paper, 16 raw SAR images from ERS 1 and ERS 2 have been selected to study the feasibility of SAR interferometry in order to extract the surface velocity fields of the studied glaciers. The data set presented in Table II includes different time intervals (one day with tandem couples, three days, and six days), different seasons, and ascending and descending passes.

\section{Large-Scale DTM}

A large-scale DTM is required for InSAR processing in order to remove the topographic fringes and to georeference the information obtained in radar geometry (unwrapped phase and complementary information such as amplitude and coherence). For topographic fringe removal, the DTM accuracy requirement increases with the baseline between the two SAR acquisitions, which makes interferograms more and more sensitive to the topography, especially in the high-relief areas of Alpine glaciers. In the georefencing step, the impact of low-resolution DTM or low planimetric accuracy can be important since in the last step, the displacement measured on the radar LOS is converted into velocity fields using the hypothesis of surfaceparallel motion in the direction of maximum slope, as described in Section V. This last step requires only a low-resolution slope estimate, but registration of the SAR measurements and the topography is error prone, especially on the margins of the narrow Alpine glaciers.

Since the 1995 aerial photographs cover only the most important glaciers and a high-resolution DTM has been produced until now only on the Mer de Glace and the lower part of the Leschaux glacier, a large-scale DTM has been used for the SAR processing. Normally, the Shuttle Radar Topography Mission (SRTM) DTM would be sufficient, even though only the Digital Terrain Elevation Data-1 resolution (about $90 \mathrm{~m}$ ) is available in Europe. However, in the studied mountainous area, the SRTM DTM is not complete due to the forshortening and shadow 
TABLE II

ERS SAR RaW Data Acquired Over the Mont-Blanc Area [B: Baselines (Parallel and Perpendicular to the Radar LOS), $e_{a}$ : Altitude of Ambiguity]

\begin{tabular}{||c|c|c|c|c|c|c|c|c||}
\hline \hline Dates & $\Delta t$ & Satellite(s) & Orbites & Frame & Pass & $B_{\|}(\mathbf{m})$ & $B_{\perp}(\mathbf{m})$ & $e_{a}(\mathbf{m})$ \\
\hline \hline $91.08 .17 / 91.08 .20$ & 3 days & ERS-1/1 & $00449 / 00492$ & 2682 & Des. & -44 & -7 & 1202 \\
\hline $91.08 .29 / 91.09 .04$ & 6 days & ERS-1/1 & $00621 / 00707$ & 2682 & Des. & 36 & 291 & 29 \\
\hline $95.07 .09 / 95.07 .10$ & 1 day & ERS-1/2 & $20830 / 01157$ & 0909 & Asc. & 17 & 52 & 162 \\
\hline $95.08 .13 / 95.08 .14$ & 1 day & ERS-1/2 & $21331 / 01658$ & 0909 & Asc. & -37 & -98 & 86 \\
\hline $95.10 .22 / 95.10 .23$ & 1 day & ERS-1/2 & $22326 / 02653$ & 2673 & Des. & -44 & -107 & 87 \\
\hline $95.12 .31 / 96.01 .01$ & 1 day & ERS-1/2 & $23328 / 03655$ & 2673 & Des. & 79 & 208 & 45 \\
\hline $96.03 .10 / 96.03 .11$ & 1 day & ERS-1/2 & $24330 / 04657$ & 2673 & Des. & 26 & 9 & 935 \\
\hline $96.04 .14 / 96.04 .15$ & 1 day & ERS-1/2 & $24831 / 05158$ & 2673 & Des. & 39 & 93 & 100 \\
\hline \hline
\end{tabular}

effects. For this paper, it has been completed using an 80-mresolution DTM provided by the French National Geographic Institute (IGN), which was built from 1980 photos by photogrammetric restitution at $1 / 60000$ scale and from digitalized contour maps at $1 / 25000$ scale. With large altitude of ambiguity as in the March 1996 ERS pair (about $900 \mathrm{~m}$ ), the impact of the resulting DTM uncertainty is still negligible in the fringe pattern. This DTM has been used for the georeferencing of the whole SAR image. In the last InSAR processing step, it was updated by the DTM computed by aerial triangulation (AT) from the 1995 photos (Section III).

\section{High-Resolution DTM Computation}

Several series of photos were selected over the Leschaux/Mer de Glace glacier. The $9 \times 9$ in (approximately $23 \times 23 \mathrm{~cm}$ ) negatives were scanned at a resolution of $15 \mu \mathrm{m}$, providing $15360 \times 15360$ pixels per image. They cover each glacier with about $80 \%$ overlap. On the 1995 acquisition over the Mer de Glace glacier (Fig. 3), the pixel size in the original photos corresponds to $36 \mathrm{~cm}$ at the bottom of the glacier (1000 m ASL) and $18 \mathrm{~cm}$ at its top (2800 $\mathrm{m} \mathrm{ASL}$ ). The plane was flying at an altitude of $4650 \mathrm{~m}$ ASL.

In the first step of the processing, the digital images are oriented using the bundle-block AT technique, which enables global restitution of a block of photos and reduction of ground control points (GCPs). This creates the possibility of working over terrain with poor geodetic point density. Bundle-block adjustment is an iterative method based on the use of photo coordinates as observations. Then, the application of the central projection method [39] enables the conversion of these observations into terrain coordinates in one step. This requires a block of photos with at least $60 \%$ overlap and $20 \%$ side-lap (often more). Moreover, a set of eight points located on both sides of the glacier and measured by GPS with an accuracy of $10 \mathrm{~cm}$ in $X, Y$, and $Z$ is needed for the orientation process. Fig. 3 shows the location of the GCPs used in the AT process. It is obvious that the distribution and number of GCPs are not optimal, especially in the inaccessible parts of the glacier. Only a few targets fixed in the past on rocks along the glacier were visible on the 1995 images. Some additional points close to huts have been measured by GPS.

The input to AT calculations consists of picking both GCPs and tie points (used to join photos together along and between strips), and their quality affects the reliability of the overall model. Point measurement uncertainty is estimated from rms

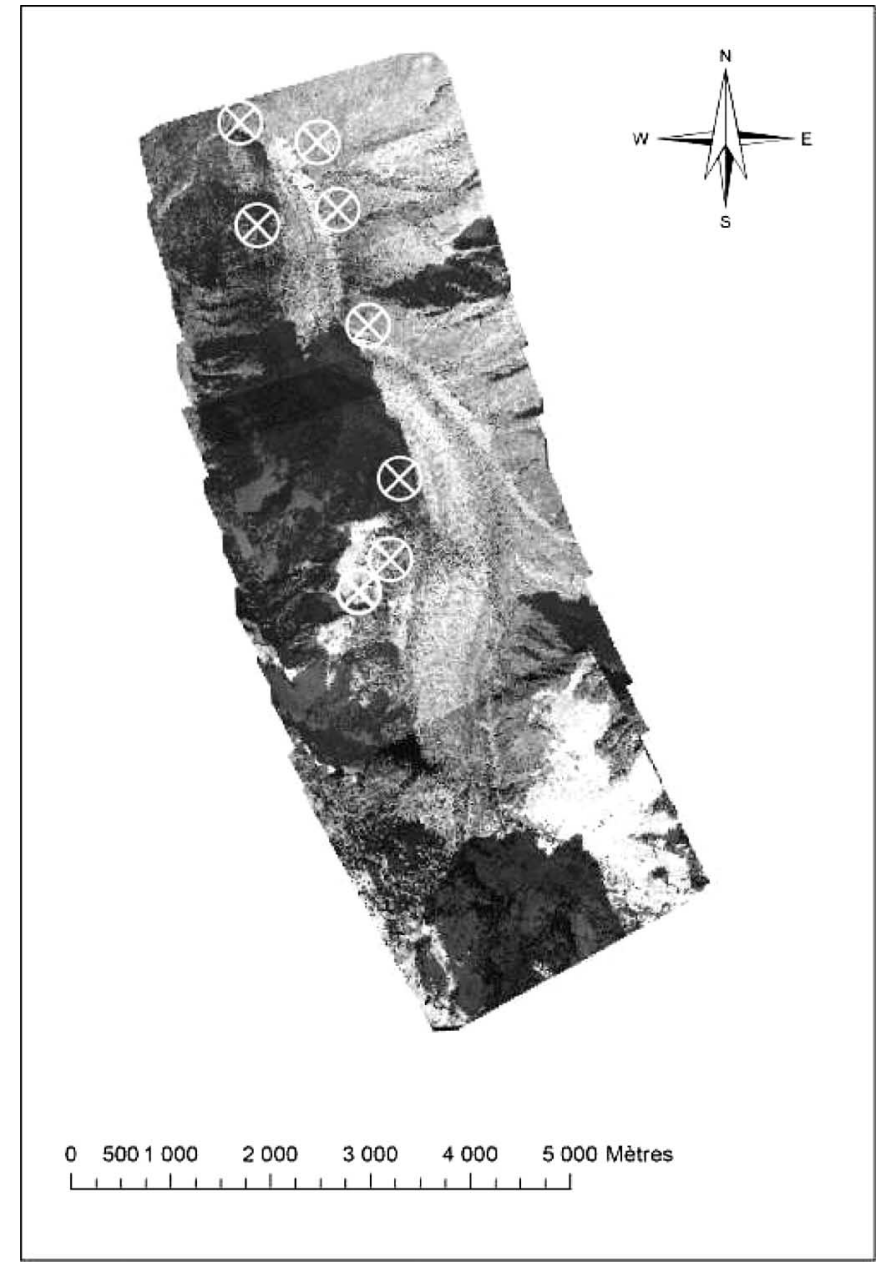

Fig. 3. Layout of the set of 13 photos that were taken over the Mer de Glace in 1995 and are entering in the AT processing. Circles represent the points measured by GPS.

errors. Finally, the main advantage of processing by the bundleblock adjustment is to produce a global and homogeneous result over the whole area.

On the Mer de Glace, approximately 3700 AT points were computed, including 2000 three-ray points (the same point measured in three overlapping images), 500 four-ray points, and about 200 five-ray points due to the high degree of overlap. Each correlated point is processed from at least three images, and this redundancy leads to high accuracy. The rms errors of the computed AT points are $\sigma_{X, Y}= \pm 20 \mathrm{~cm}$ and $\sigma_{Z}= \pm 30 \mathrm{~cm}$. 
These images are then used to compute about 5 million complementary points on a regular grid by photogrammetric matching techniques (using the KLT software package) based on the correlation of image patches in two or more successive images. Break lines and structure lines are defined by manual stereoscopic measurements. Break lines and structure lines are specific edges of topographic significance on the terrain. They define physical discontinuities in slope and are materialized by linear features. The aerial photos were acquired during the summer, so only a few areas were covered by snow in the upper part of the glacier. Matching was problematic when saturation of the optical images occurred, leading to failure of automatic correlation. Thus, manual stereoscopic measurement was necessary to supplement the terrain model. Specific problems also arise in matching ice cracks. Manual points have to be taken at the top and bottom of crevasses. The result is controlled by stereo-viewing (superimposing previously matched points and selected stereo pairs). The global result is obtained with $80 \%$ automatic or semiautomatic measurements, where semiautomatic processing entails guidance from the operator, who increases the density in weak areas by stereoscopic measurements. About $20 \%$ are completed manually in areas where steep slopes or poor contrast prevents reliable matching.

At this stage of the processing, a DTM can be computed with a resulting horizontal resolution ranging from 2 to $5 \mathrm{~m}$ depending on the slopes. Generally, a 5-m grid is used, except in very steep areas, where one point for every $2 \mathrm{~m}$ was necessary in order to guarantee the required altimetric accuracy. The accuracy of the final DTM, despite manual intervention, is assessed to lie in the accuracy interval announced previously $\left(\sigma_{X, Y}=\right.$ $\left.\pm 20 \mathrm{~cm}, \sigma_{Z}= \pm 30 \mathrm{~cm}\right)$ since an experienced operator reaches at least that measurement precision.

The resulting final DTM over Mer de Glace is shown in Fig. 4. By superimposing the orthoimages processed with the 1995 photos on the produced DTM, a 3-D model of the Mer de Glace is obtained (Fig. 5).

\section{D-INSAR PROCESSING}

Despite many applications already using differential SAR interferometry, the processing of such data and the extraction of the sought-after information are still a difficult task. This is even more difficult in the context of the proposed test site with high-relief topography, large and irregular displacements, and snow and ice backscattering mechanisms, which are still under investigation [40]. In this section, results obtained by different processing chains are presented to evaluate the feasibility and the limitation of D-InSAR glacier monitoring with ERS data.

\section{A. SAR Processors}

In this paper, two standard D-InSAR processors have been used: Differential Interferometric Automated Process Applied to Survey Of Nature (DIAPASON) and Repeated Orbit Interferometry Package (ROI-PAC) software packages. The first results obtained with an original InSAR time-domain processor called the SYnthèse TEmporelle Radar (SYTER) are also presented.

1) Standard Processors: The standard DIAPASON processor provides a complete D-InSAR processing chain that allows

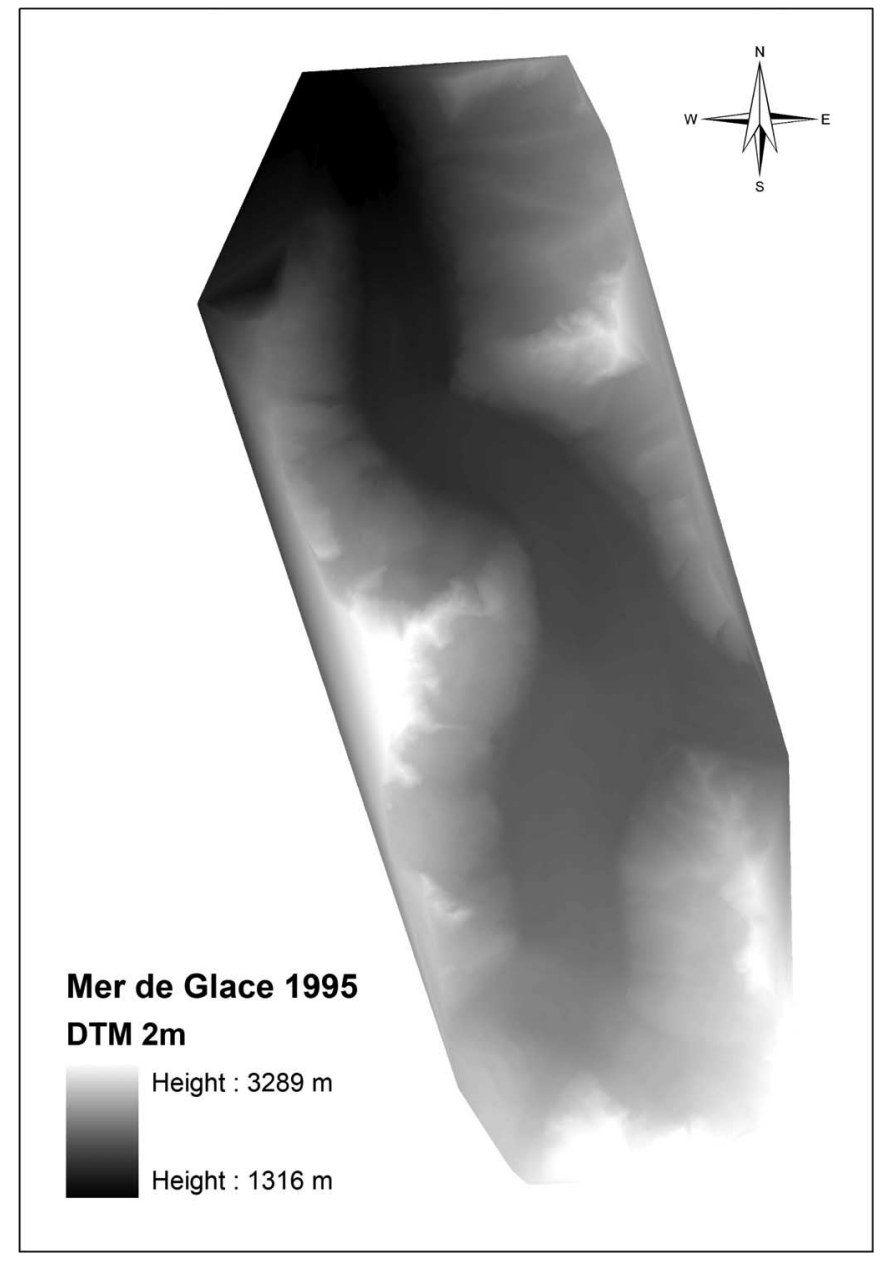

Fig. 4. Mer de Glace DTM processed by photogrammetric techniques.

scientists from different application fields (e.g., volcanology, seismology) to obtain meaningful results from the use of SAR interferometry to measure displacements [13]. This processing chain was developed at the Centre National d'Etudes Spatiales [41] in the beginning of the 1990s and provides better results when the processing starts with raw data instead of singlelook complex (SLC) images. The focusing is performed in the frequency domain to reduce the computation load, which was a critical issue at that time. DIAPASON can be used without a DTM (using a flat earth with a constant elevation), which leads to reasonable measurements in the case of very large altitude of ambiguity. When DTMs are introduced at the interferogram generation stage, the registration step is improved, and the intensity, coherence, and phase images can be computed directly in the DTM geometry. However, generating interferograms in the radar geometry is more appropriate for further processing such as filtering or phase unwrapping.

Another D-InSAR processor that is widely used in the academic and research community is the ROI-PAC. From the initial experiments in spaceborne radar interferometry [42], ROI-PAC has been developed through the collaboration of many researchers at the Jet Propulsion Laboratory and Caltech [43]. It uses raw radar data, telemetry information, and DTMs for generating displacement maps [44]. In this processing chain, DTMs become necessary only after the interferogram 


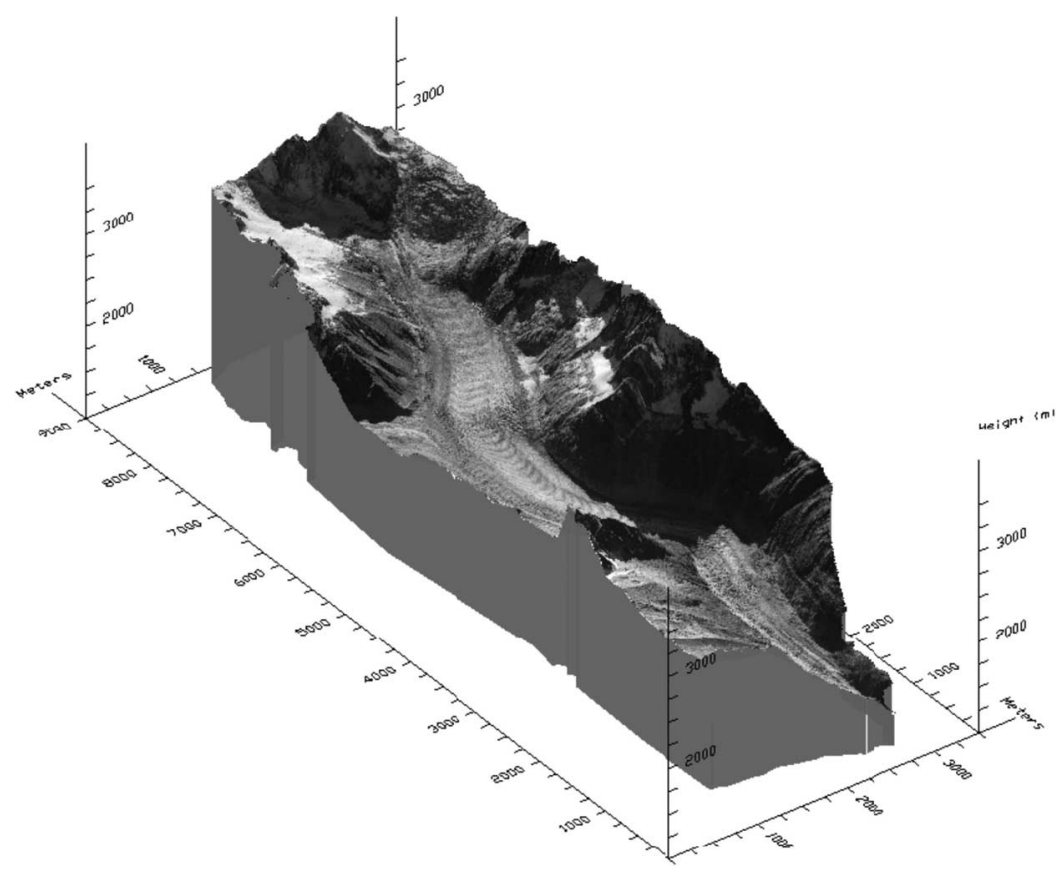

Fig. 5. Mer de Glace glacier 3-D model (orthophotos from 1995 that were draped on the computed DTM).

generation stage to enable topographic fringe removal and precise orbital phase corrections. It also allows resampling of the results in ground geometry.

It is important to notice that in both cases, the SAR focusing is performed with a mean altitude hypothesis, which is valid with ERS data and slow height variations. This hypothesis tends to introduce focusing errors in areas with strong topographic relief: Indeed, there is, for example, almost a 4000-m-height difference between Chamonix valley and the Mont-Blanc summit, corresponding to a foreshortening that can be compared to the ERS field of view (several kilometers). For high-resolution data, this effect is more severe, and a DTM is usually required for SAR synthesis.

2) Temporal-Domain Processor: To overcome the previous difficulty in specific areas, such as the studied glaciers, and to benefit from accurate DTM information earlier in the processing, an original approach is currently being developed at Télécom Paris [45]. It is based on the processing of raw data in the temporal domain. The main ideas of the proposed SAR processing consist of the following.

- Using local circular approximation of the satellite orbit and the Earth rotation to take into account the relative displacement of the imaged points. This allows us to search for the closest point approach (CPA), which is the time of the shortest distance between the Earth target point and the sensor. The CPA corresponds to a zero Doppler Centroïd value. All the relative positions of the Earth target point can be tabulated around this CPA. Actually, in this approach, nonzero Doppler Centroïd data correspond to a slight squint angle in the acquisitions.

- Performing in the time domain a coherent summation of the delayed complex raw data. Delays required for this beamforming are deduced from previous tabulated relative positions. Subaperture images can be obtained by selecting a reduced set of raw data.
- Choosing a ground range geometry for reconstructed pixels. In this way, the computation of interferograms does not require any coregistration as, by introducing the baseline in the SAR processing, the two SAR images are directly obtained in the same ground geometry. Moreover, in order to obtain two images with the same Doppler Centroïd, data are processed with squint angles corresponding to the same subaperture. This allows us to reduce the noise in the resulting interferogram.

Fig. 6 presents the results obtained with the three SAR processors previously described. The fringe pattern visible along the diagonal (from upper left-hand side to bottom righthand side) corresponds to the Mer de Glace and Leschaux glaciers' displacement. The three fringe patterns on the bottom left-hand side also correspond to three small glaciers moving West toward the Chamonix valley. Global fringe patterns obtained by the different processors are similar. Differences in shape and orientation are due to different sampling geometries: The ROI-PAC and DIAPASON results are in radar geometry, whereas the temporal processor result is in the ground geometry. The reduced noise and apparently smoothed result of the temporal approach are due to the common band filtering resulting from the selection of the same subaperture.

At this stage, the SYTER experimental processor takes only a constant baseline and the distance to the geoid into account. The next development will introduce the precise orbits and the elevation provided by the DTM in the sensor-target distance computation. The results obtained by the ROI-PAC processor with the precise obits from Delft University, Delft, The Netherlands, are used in the following steps.

\section{B. Interferogram Generation}

1) Glacier Visibility: In order to assess the glacier visibility in ERS ascending and descending passes, several simulations 
(a)

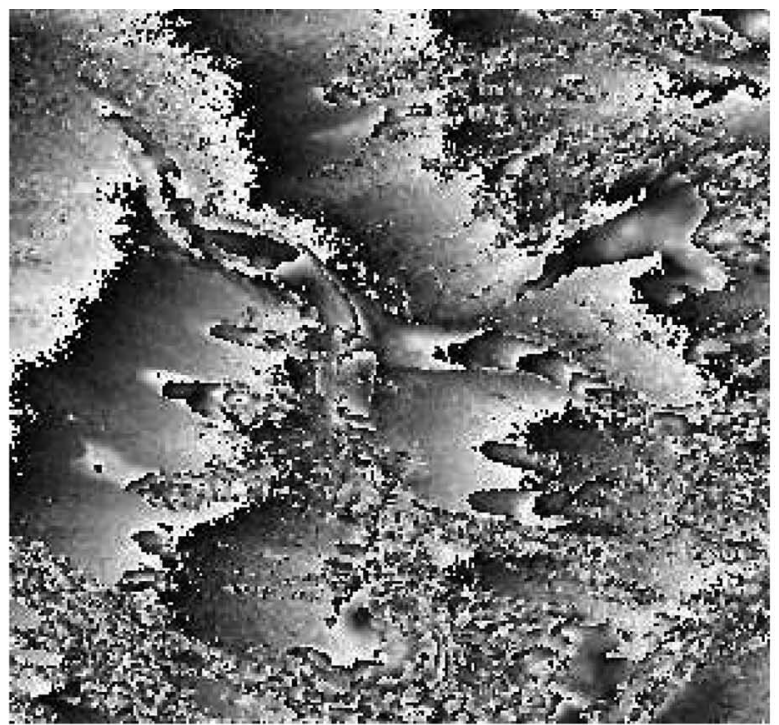

(b)

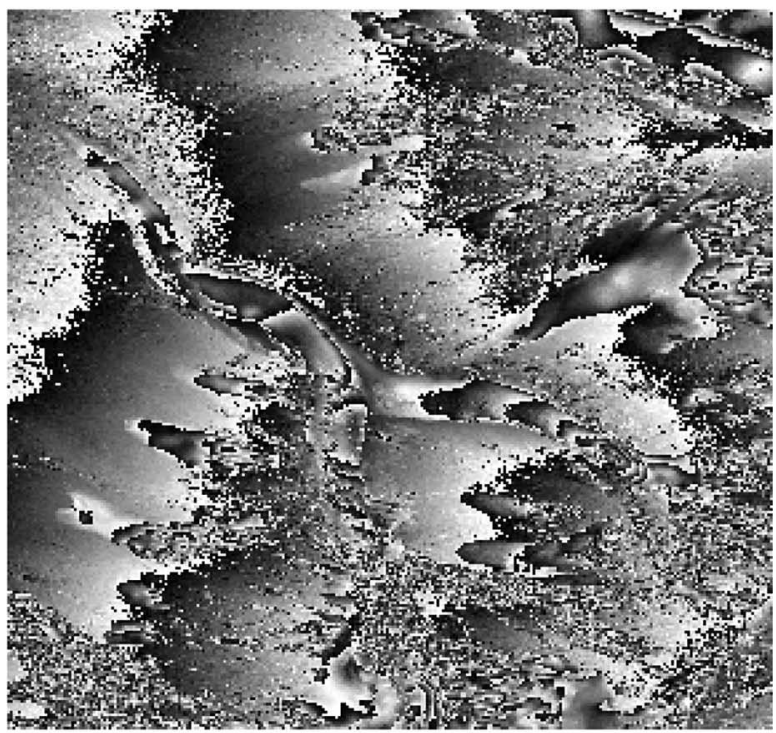

(c)

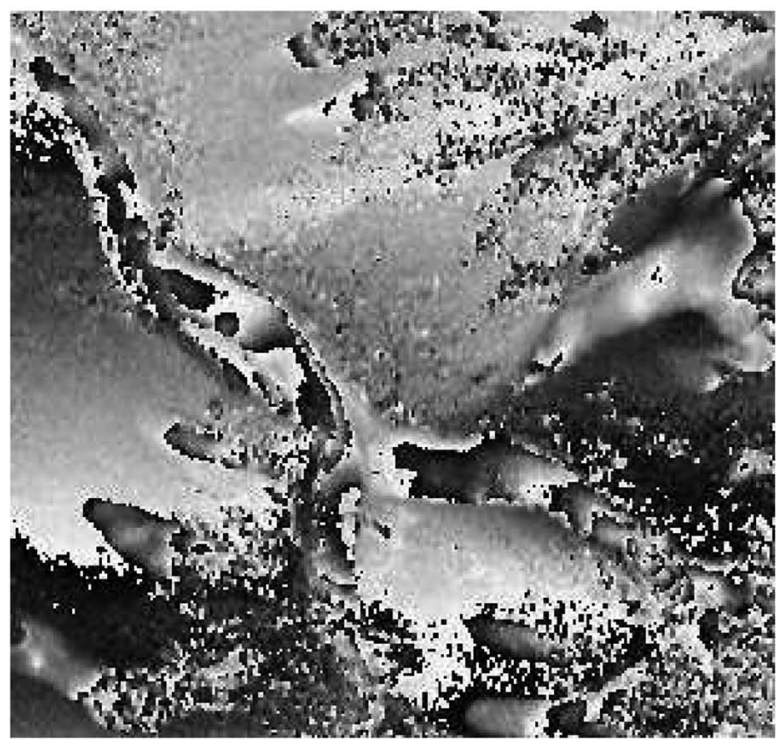

Fig. 6. ERS-1/2 March 1996 tandem interferometric phase after orbital fringe correction. (a) and (b) DIAPASON and ROI-PAC results in slant range geometry. (c) Temporal-domain processing result in ground range geometry. have been performed with the DTM of Fig. 7(a). A SPOT 2 multispectral orthoimage where the main glaciers are clearly visible [Fig. 7(b)] is used to illustrate the results. The masks, which correspond to the nonvisible regions (layover, shadow), are shown in red over the SPOT optical image. The nonvisible areas for ERS ascending and descending acquisitions are presented in Fig. 7(c) and (d), respectively. Due to the orientation of the Argentière and Mer de Glace glaciers, the results show that approximately $85 \%$ of their surface is visible from ERS descending orbits. On the contrary, less than $20 \%$ of the two studied glacier surfaces can be investigated from ascending orbits. Accordingly, only the descending ERS-1/2 images may provide useful information for velocity assessment by means of D-InSAR processing.

2) Coherence Analysis: The descending ERS-1 three-day interval pair acquired during the summer of 1991 has been processed by the processors presented in Section IV-A to ensure that the results and the associated conclusions are not influenced by processing artifacts. The obtained interferograms have good overall quality, showing a high level of coherence on the nearby mountains and in the Chamonix valley. However, the coherence is low on the studied glaciers [Fig. 8(b)]. Despite the lack of glacier visibility, the same result can be observed with the ascending pairs during the summer of 1995 [Fig. 8(d)]. The loss of interferometric coherence can be explained by either a large change of the glacier surface state or a strong glacier displacement that would affect the global coregistration algorithm.

In order to investigate which assumption holds, controlled displacements were introduced in artificial interferograms computed by using twice the same acquisition (ROI-PAC SLC image from ERS1 1991-08-17). The displaced images were obtained by SLC resampling (four-point cubic convolution [46]) and then by shifting in the glacier flow direction by multiples of 0.25 pixels. Several interferograms were constructed between the original SLC image and the displaced SLC images. Fig. 9 shows the coherence mean and standard deviation computed on these artificial interferograms within a mask including only the Mer de Glace and Leschaux glaciers. The resulting plot shows that a satisfactory coherence level can be obtained even for displacements that are much larger than those expected for the studied glaciers within intervals of a few days: in the absence of any other decorrelation factor, the coherence level is above 0.6 for displacement up to $15 \mathrm{~m}$.

With the real ERS August 1991 three-day interferogram, the displacement of the Mer de Glace and Leschaux glaciers is approximately only $1 \mathrm{~m}$, whereas the coherence mean is equal to 0.2 [see Fig. 8(b)]. This loss of coherence in summer pairs can be interpreted only by glacier surface changes probably due to ice melting and variation in the number and position of elementary backscatters in the resolution cell. An empirical model derived from observed ablation confirms this interpretation: Each positive degree yields $6.6 \mathrm{~mm}$ of ablation per day [34]. With the summer positive temperature often encountered at daytime in the studied glaciers, the ablation is too important compared to the $\mathrm{C}$-band $5.6-\mathrm{cm}$ wavelength to preserve interferometric coherence. This conclusion is also consistent with the results reported by Fischer et al. [47] over Iceland glacier 
(a)

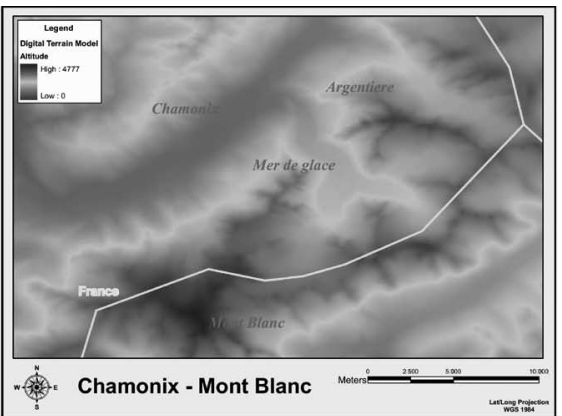

(c)

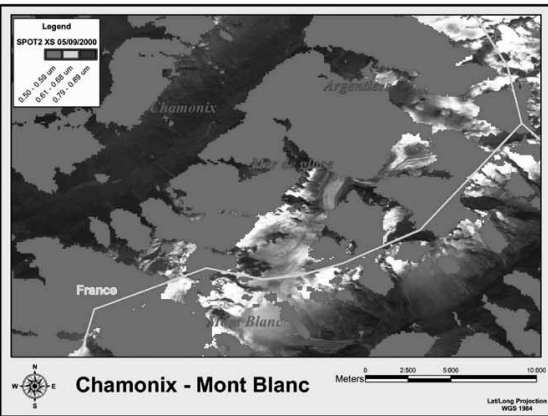

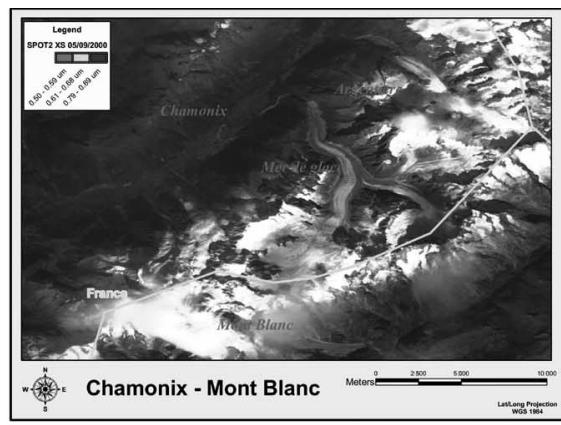

(b)

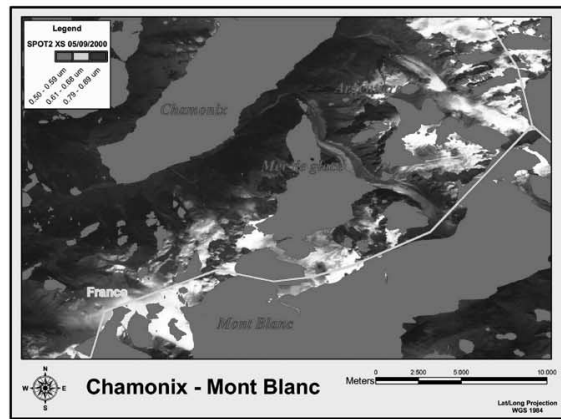

(d)

Fig. 7. ERS satellite visibility assessment. (a) Large-scale DTM. (b) Orthorectified SPOT-2 multispectral image. (c) Ascending ERS visibility (nonvisible parts masked in red). (d) Descending ERS visibility.

surges: they succeeded in measuring displacement that is often greater than $1 \mathrm{~m} /$ day (up to $7 \mathrm{~m} /$ day) mostly in ERS tandem winter interferograms, whereas changes of glacier surface due to precipitation, melt, and wind cause fast decorrelation of the phase signal.

So, the most likely explanation of the summer results is that on the Mer de Glace and Argentière glaciers that are below $3200 \mathrm{~m}$, the interferometric coherence at three-day intervals is completely lost because they are below the $0{ }^{\circ} \mathrm{C}$ isotherm (snow line), which is often above $4000 \mathrm{~m}$ during the summer according to the Chamonix weather station and an assumed lapse rate of $6^{\circ} / \mathrm{km}$. Note also that the coherence map seems to be a good parameter to automatically delimitate glaciarized areas: the surroundings have either an intermediate coherence level in forested areas or a good coherence level at higher altitudes, where rock and low vegetation do not create volume decorrelation.

To investigate the potential of ERS tandem SAR interferometry during the rest of the year, four descending InSAR pairs from October 1995 to April 1996 have been processed (cf. Table II). After the ROI-PAC orbital and topographic fringe removal, an adaptive neighborhood filter [48] has been applied to reestimate the phase and the coherence. Such filtering is required, especially for large baselines, to obtain a sufficient number of samples to reduce the phase noise and the coherence bias and noise. This approach prevents smoothing of edges such as glacier margins and strong backscatterers, which might be useful for further analysis [38].

Among the four interferograms illustrated in Fig. 10, the highest coherence can be observed in the March pair, which has the smallest perpendicular baseline and is still acquired in the cold season. The "new-year" pair has the lowest coherence due to the volume decorrelation caused by the large baseline. Over the Mer de Glace, Leschaux, and Argentière glaciers, the results show good preservation of coherence in the winter interferograms (December and March), whereas in the October and April interferograms, the coherence is well preserved only in the upper parts of the glaciers (south east).

Accordingly, we can conclude that in three-day intervals during the summer season, the variations of the glacier surface state in temperate alpine glaciers such as those of the Chamonix valley are stronger than C-band SAR interferometric tolerances for ERS data. By contrast, coherence is preserved in tandem pairs acquired in the winter season and allows the measurement of glacier displacement at this time of the year. The limitation in using InSAR in intermediate seasons depends on the meteorological conditions and the glacier's altitude. In the following, the most correlated interferogram (March 1996) will be used to illustrate the processing steps applied to obtain velocity fields over the studied glaciers.

3) Phase Analysis: Generally, the interferometric phase between two SAR images is assumed to contain independent contributions from orbit geometry, surface topography, surface motion, and atmospheric changes between the two acquisitions [17].

Due to the fact that the glacier surface is very small compared to a full satellite frame, only local (not regional) atmospheric changes can affect InSAR measurements over the studied glaciers. As radiowave velocity mainly depends on local water vapor pressure and temperature (Smith and Weintraub formula) [49] and as saturation water vapor pressure is rather small near $273 \mathrm{~K}$ (i.e., the surface glacier temperature), one-day variations should be minimal in winter.

This can be verified by comparing several different pairs collected during the same season. The similarity of the glacier fringe pattern from the four tandem interferograms presented in Fig. 10 can be visually observed in the high and medium coherence areas. This is confirmed by the wrapped phase 
(a)
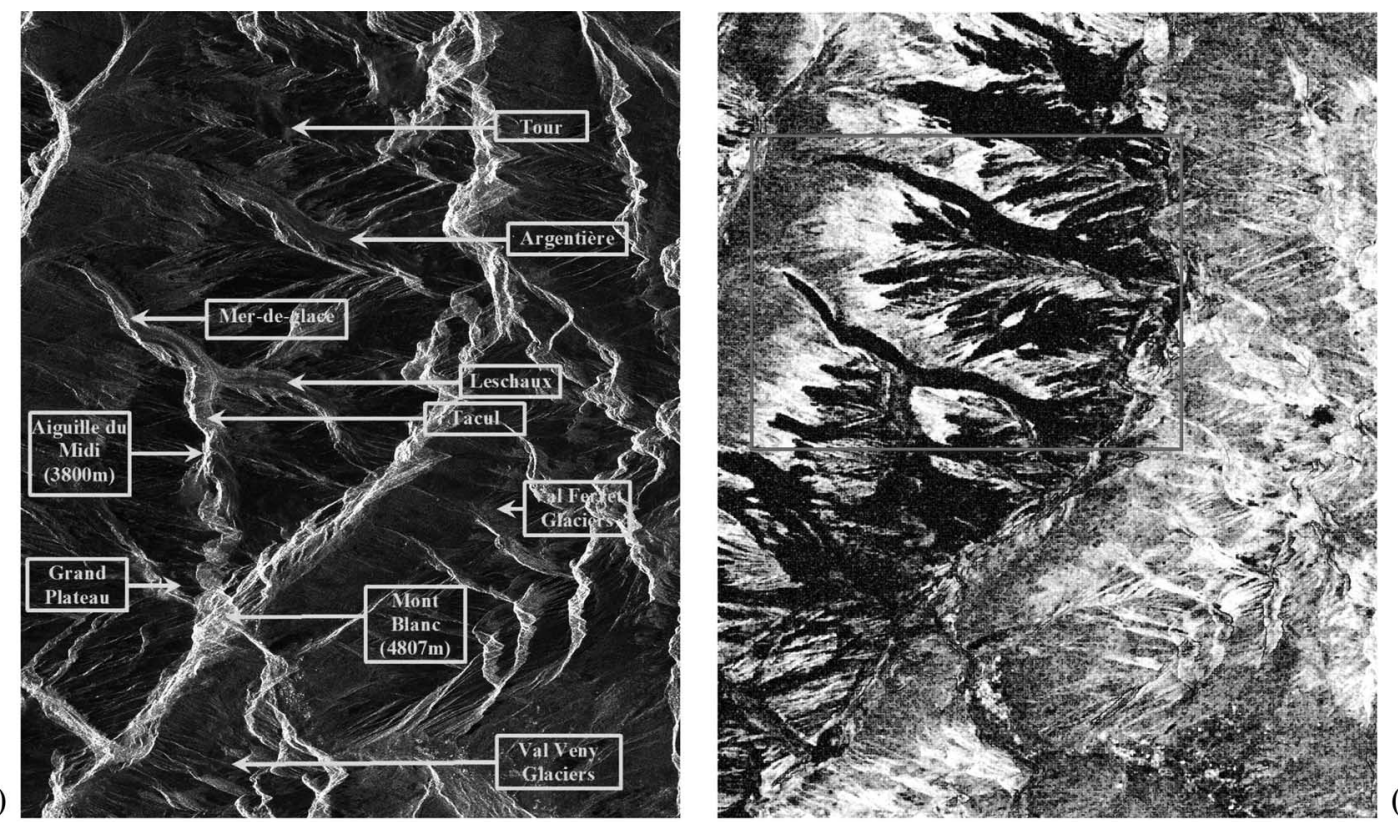

(c)
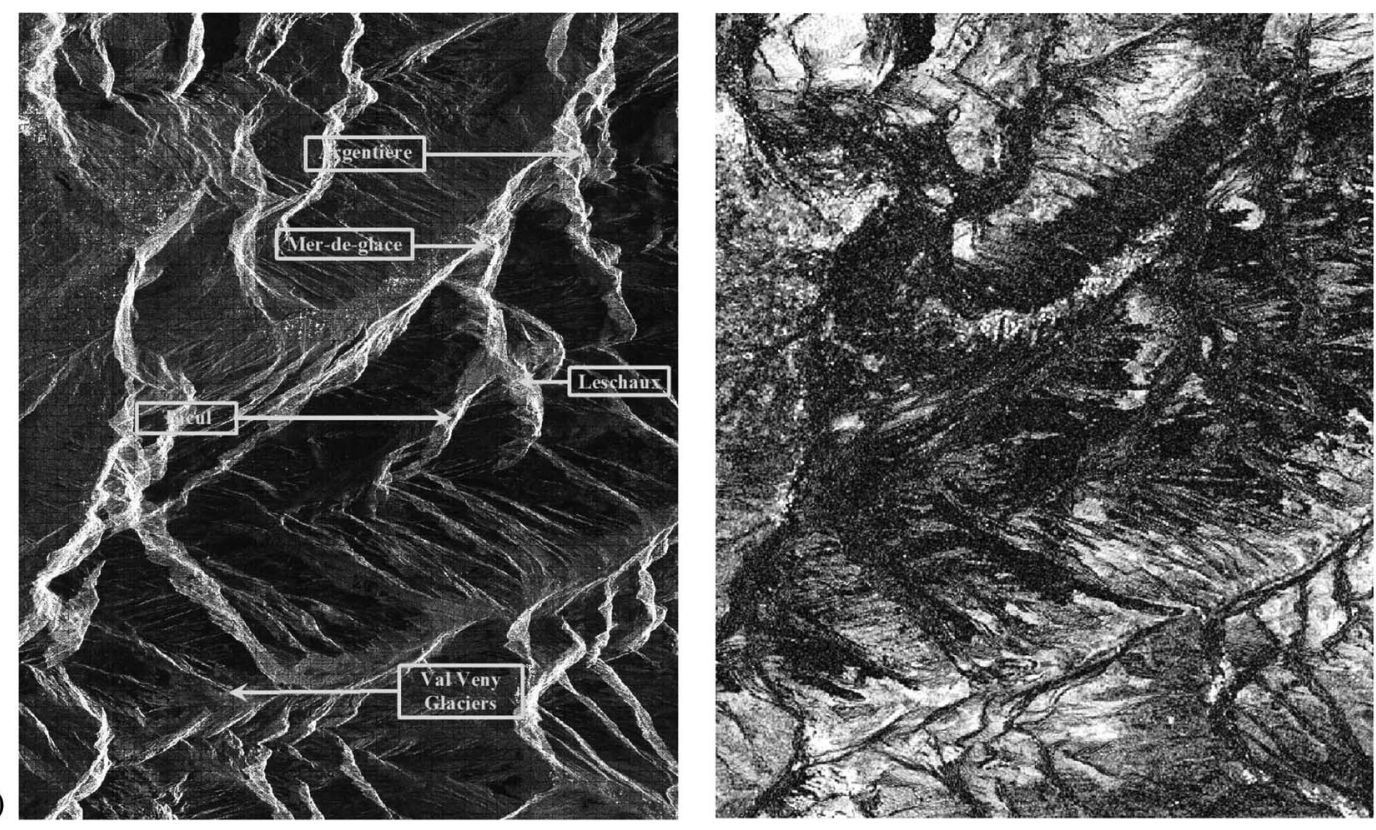

(d)

Fig. 8. (a) and (b) ERS1 three-day descending pass interferogram for the summer of 1991, annotated amplitude and coherence map of $1251 \times 1531$ pixels. The rectangle marked in red will be used in the sequel for further illustration. (c) and (d) ERS-1/2 one-day ascending pass interferogram for the summer of 1995, annotated amplitude and coherence map of $837 \times 1024$ pixels. These images are in radar geometry (slant range, azimuth) and obtained from SLC data by $1 \times 5$ multilooking.

differences between interferograms presented in Fig. 11. The difference is almost zero with two consecutive interferograms [March and April pairs, Fig. 11(a)] and slightly increases in some parts of the glaciers when more distanced periods are compared: the March/December pairs [Fig. 11(b)] and the March/October pairs [Fig. 11(c)]. The observed differences are also in quite good agreement with the in situ measurements presented in [50]. According to these results, at the scale of the glaciers located in the Alps, the atmospheric perturbations can be considered negligible in winter.

The removal of orbital and topographic fringes can be performed by using the large-scale DTM from Fig. 7(a) and precise orbit information from Delft University [44]. The visual analysis of the four interferograms presented in Fig. 10 shows the accuracy of the processing: out of the glaciers, the phase is almost constant along track and less than half a fringe appears in range direction, even with different perpendicular baselines and 3000-m height variations between the Chamonix valley and the mountain summits.

According to these results, the remaining fringe patterns can be considered to correspond only to the glacier one-day displacement, projected on the SAR LOS, and wrapped in the $[0,2 \pi]$ interval.

\section{Phase Unwrapping and Orthorectification}

To extract quantitative velocity information from the interferometric fringes shown in Fig. 10, the phase must be unwrapped. 


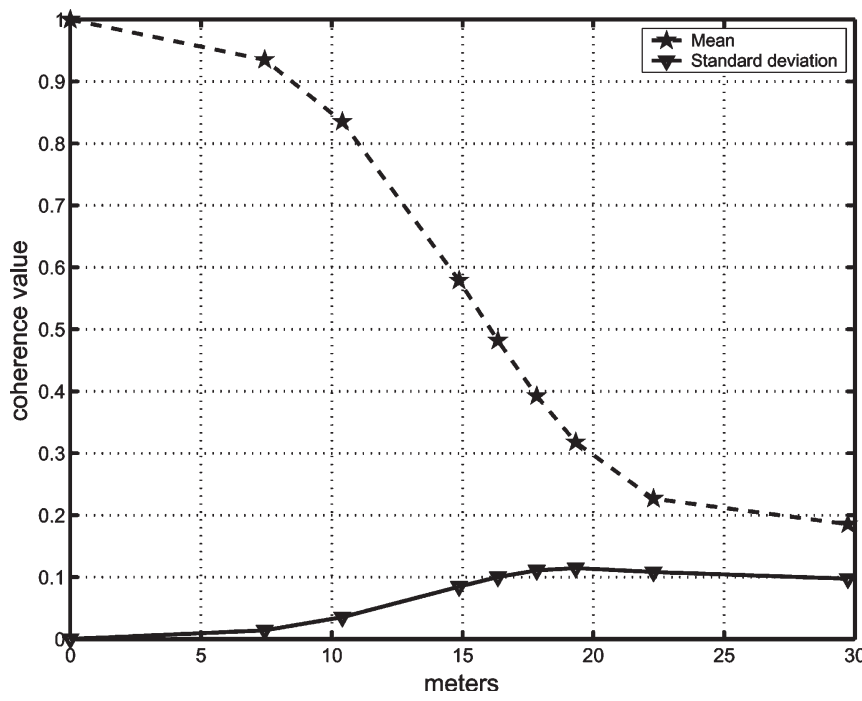

Fig. 9. Coherence values function of the artificially induced displacement created by using twice the same acquisition (ERS-1, August 17, 1991). Coherence mean and standard deviation are measured after $5 \times 1$ complex averaging on the Mer de Glace and Leschaux glaciers.

Several obstacles make fully automatic phase unwrapping difficult in the case of glacier displacement fringes. First, at the glacier margins, the motion phase signal is discontinuous with the rest of the interferogram, which should be a constant when all geometrical effects are perfectly corrected (orbital and topographic fringe removal). Depending on the studied glaciers, some parts such as the top of the accumulation area might move very slowly and allow the assumption that the velocity is close to zero in these areas. Accordingly, it is possible to assume that there is no displacement within one day for ERS tandem interferograms in such areas and to use them as a zero reference for the phase unwrapping. In the case of the Argentière glacier, the accumulation area is visible in SAR descending passes, but the surface topography is quite steep, which does not allow such an assumption. In the case of the Mer de Glace and Leschaux glaciers, motionless parts can be found in the Mallet glacier at the top of the Leschaux, but with the ERS $23^{\circ}$ incidence angle, this part of the glacier is not visible. When there is no zero-speed area connected to the glacier in the interferogram, the observed fringe pattern can be unwrapped, but the result is obtained with an unknown offset. This offset can be found as soon as the motion of one point is known (by ground measurement for instance). This difficulty is increased when the glacier surface is separated in several disconnected parts because of the SAR geometry (shadow/layover) and the lack of coherence or aliasing, which occurs when the glacier accelerates, in ice fall areas for instance: the Nyquist criterion is not satisfied due to the image low sampling compared to the narrow fringe pattern. In this case, for the lowest part of the Argentière glacier for instance, a multiple of $2 \pi$ is unknown between the different unwrapped parts of the glacier. This problem can be solved by complementary approaches such as speckle tracking [23] or measurement of the displacement of a coherent target to find the right multiple of $2 \pi$.

The two main approaches conventionally used to perform phase unwrapping are either local methods based on branchcut algorithms, which unwrap the phase by propagation along (a)
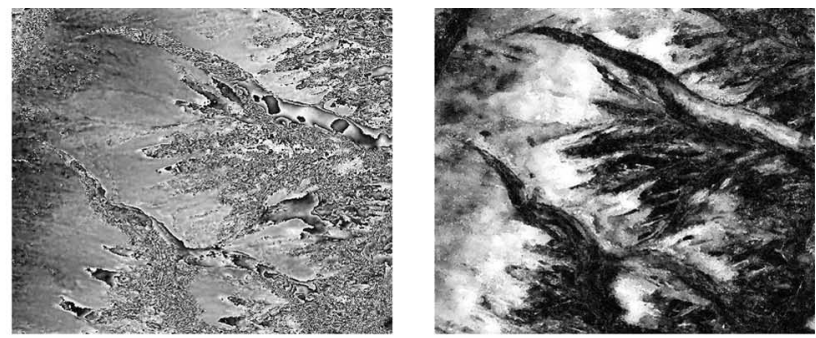

(b)
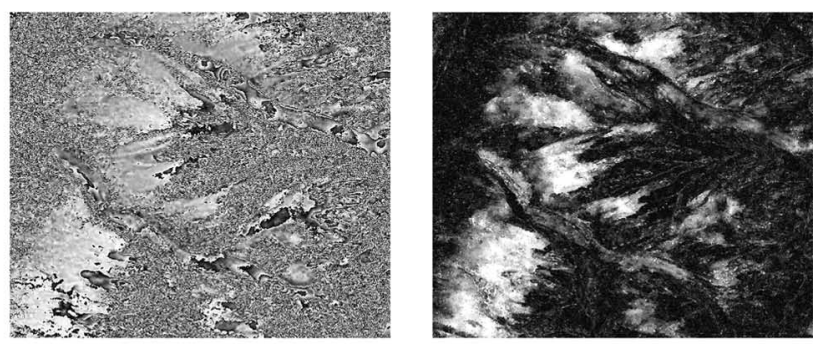

(c)
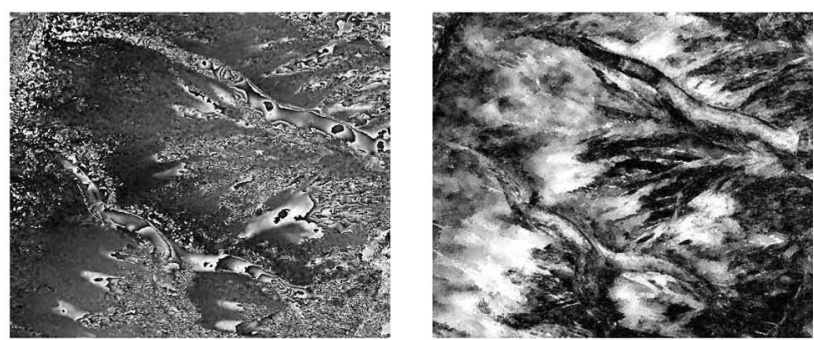

(d)
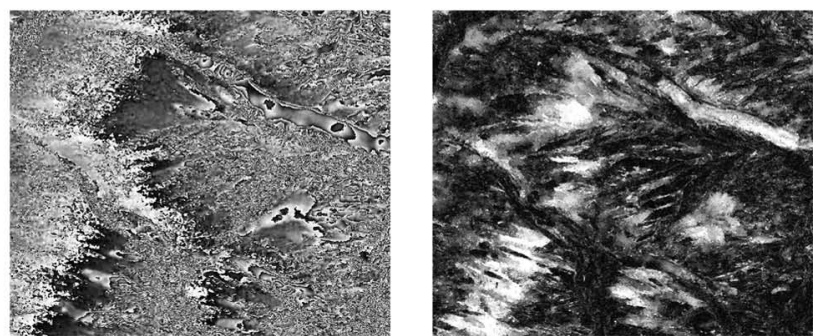

Fig. 10. ERS-1/2 tandem interferograms over the Mer de Glace/Leschaux and Argentière glaciers area $(600 \times 700$ pixels $)$. Differential phase and coherence filtered by amplitude-driven adaptive neighborhood. (a) October 22-23, 1995. (b) December 31, 1995-January 1, 1996. (c) March 10-11, 1996. (d) April 14-15, 1996.

paths as safe as possible [51], or global methods based on least square minimization of the distance between the wrapped phase gradient and the resulting unwrapped phase gradient [52]. With the first approach, the misplacement of branch cuts yields to the propagation of errors, which are multiples of $2 \pi$. The second approach has the advantage of allowing the detection and visual assessment of phase-unwrapping errors by computing the wrapped difference between the interferogram and the result.

To reduce the phase noise and to obtain a coherence level that reveals unreliable phase areas, the ROI-PAC initial $5 \times 1$ interferogram is filtered using local frequency estimation [53] and adaptive neighborhoods [48]. The filtered wrapped phase and associated coherence are illustrated in Fig. 10(c). Then, the weighted least squares phase-unwrapping approach has been applied to unwrap the phase over the Mer de Glace/Leschaux and Argentière glaciers. In order to avoid the influence of surrounding discontinuous fringes and corrupted areas, binary weights have been computed from the manual selection of the 
(a)

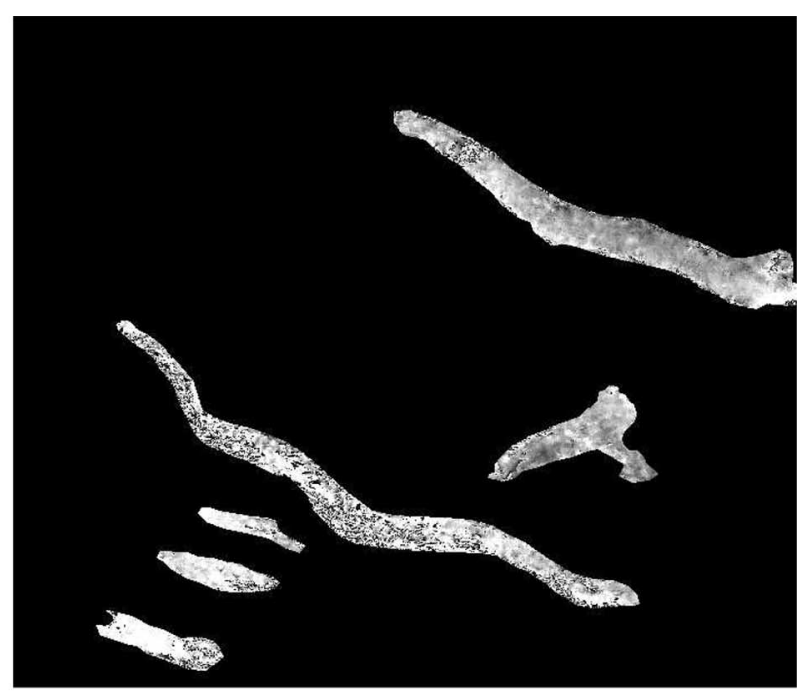

(b)

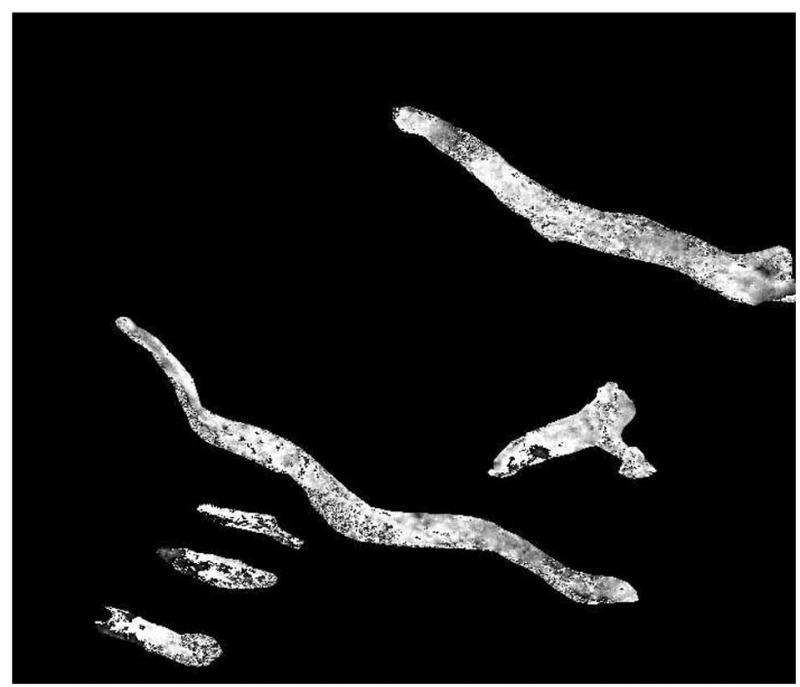

(c)

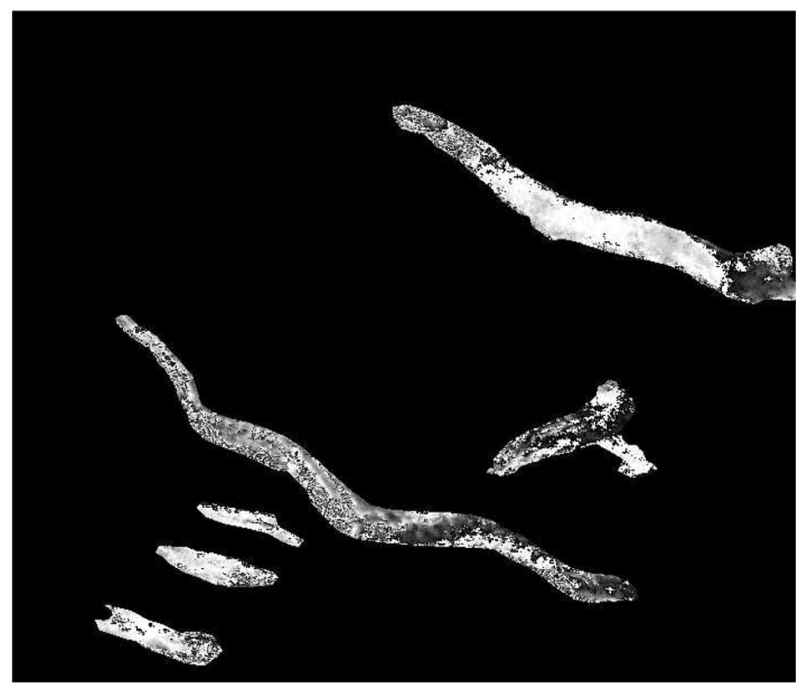

Fig. 11. Wrapped phase differences between interferograms presented in Fig. 10. (a) April 14-15, 1996 and March 10-11, 1996. (b) December 31, 1995-January 1, 1996 and March 10-11, 1996. (c) October 22-23, 1995 and March 10-11, 1996.

glacier SAR visible parts. The displacement field resulting from this unwrapping has an unknown offset on each glacier since they are disconnected.
Finally, the whole image is orthorectified, enabling easier computation of the final velocity field and comparison with ground measurements. This step is performed using the ROI-PAC software and the combined DTM described in Section II-C. It is based on the simulation of noise-free intensity images in SAR geometry using the distance to the satellite orbit and the local slope orientation provided by the DTM. Once the simulated image is registered on the real satellite image, the geometrical transformation is coded as a "lookup table," which provides the position in the SAR data of each DTM pixel illuminated by the radar. This allows to resample on the DTM grid any parameter initially computed in SAR geometry using, for instance, a bilinear interpolation.

Once the unwrapped phase is georeferenced, the unknown offsets can be set according to the knowledge of zero displacement areas or by using in situ measurements. One ground measurement point is necessary for each separated glacier, with a conversion into SAR LOS one-day displacement. Fig. 12 presents the georeferenced amplitude and coherence, which can be used to assess the confidence in the unwrapped phase. The unwrapped georeferenced differential phase is overlapped over a high-resolution airborne orthophoto to illustrate the portion of the glaciers that has been unwrapped and the geocoding accuracy of the database formed by SAR and optical orthoimages.

\section{Motion Estimation}

This section discusses the last stage of the processing: the use of the DTM to convert the one-day displacement field measured on the SAR LOS into a glacier velocity field. It presents the final results, comparisons with ground measurements, and uncertainty assessment.

\section{A. From SAR LOS Displacement to Glacier Velocity}

Due to the visibility of the studied glaciers with ERS data (Section IV-B1), the velocity field can be measured only through its projection on the LOS of descending acquisitions. The missing information is obtained by using an accurate DTM of the glacier surface and hypothesis often used when there is no reliable complementary information source. The hypotheses are given as follows:

- SPF assumption, which does not take the submergence/ emergence velocity into account [30];

- direction of the maximum averaged downhill slope, which does not take a possible sliding component into account [15].

According to these hypotheses, the following steps are performed.

- In each pixel of the DTM, the two components of the elevation gradient are computed to derive the slope $S l$ and orientation $O r$ angles of the glacier surface according to the angle conventions illustrated in Fig. 13. Then, the three-component unit vector $\vec{E}_{m}$ provides the main slope direction

$$
\vec{E}_{m}=\left[\begin{array}{c}
\cos (S l) \cdot \cos (O r-\pi) \\
\cos (S l) \cdot \sin (O r-\pi) \\
-\sin (S l)
\end{array}\right] .
$$


(a)

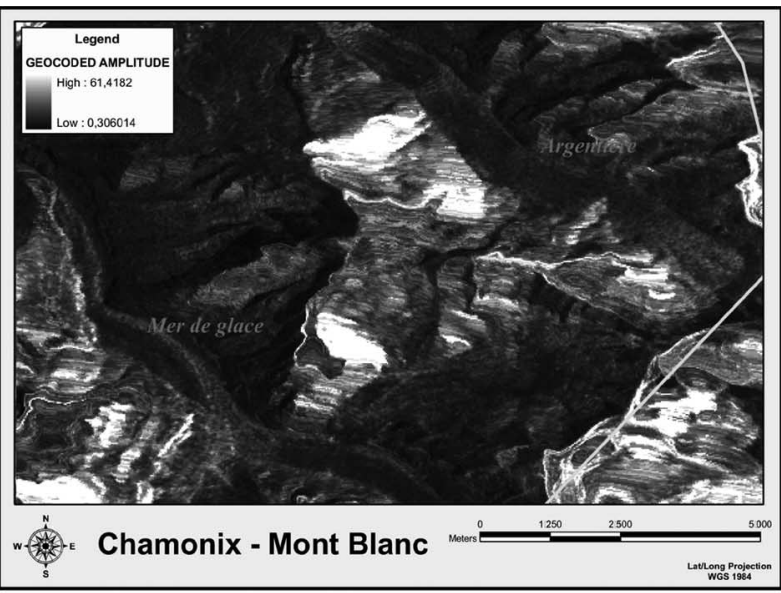

(b)

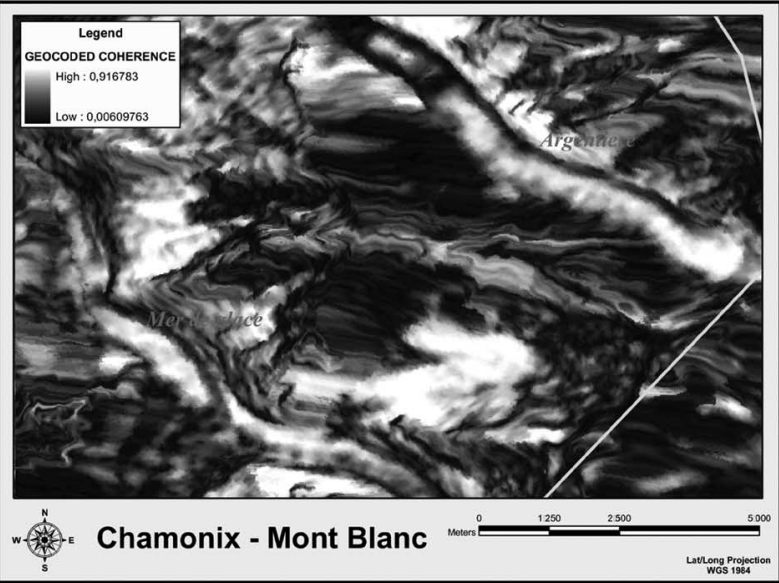

(c)

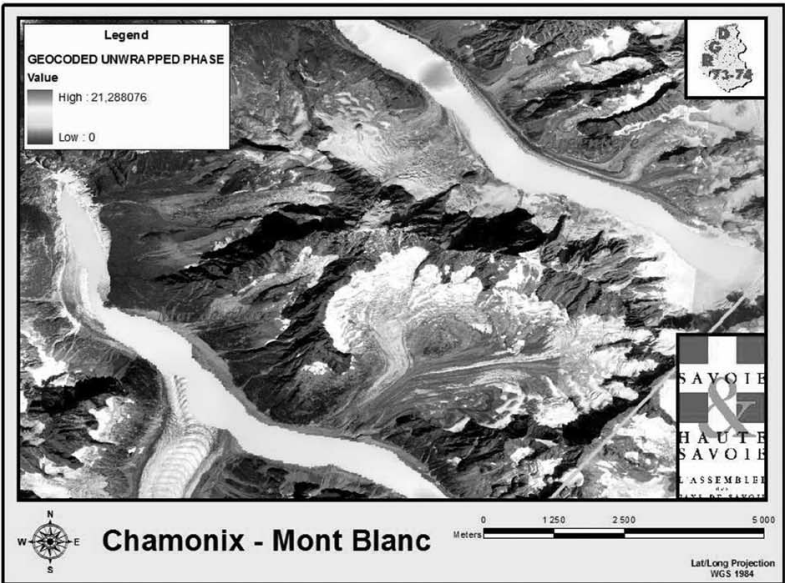

Fig. 12. ERS-1/2 tandem March 1996 interferogram. (a) and (b) Georeferenced amplitude and coherence. (c) Georeferenced unwrapped differential phase of the Mer de Glace and Argentière glaciers overlapped on an airborne orthophoto provided by the RGD-73/74; the color scalebar corresponds to the one-day LOS displacement in centimeters.

- In each pixel of the unwrapped phase image, the orientation of the LOS and the displacement along the movement direction are computed. First, the direction of the satellite must be determined with precision. Two angles are needed as parameters in the model, i.e., vertical and horizontal incidences. Vertical incidence $i n c_{v}$ is the conventional wave incidence angle, while horizontal incidence $i n c_{h}$ is the angle between the horizontal projection of the LOS and the local parallel of latitude
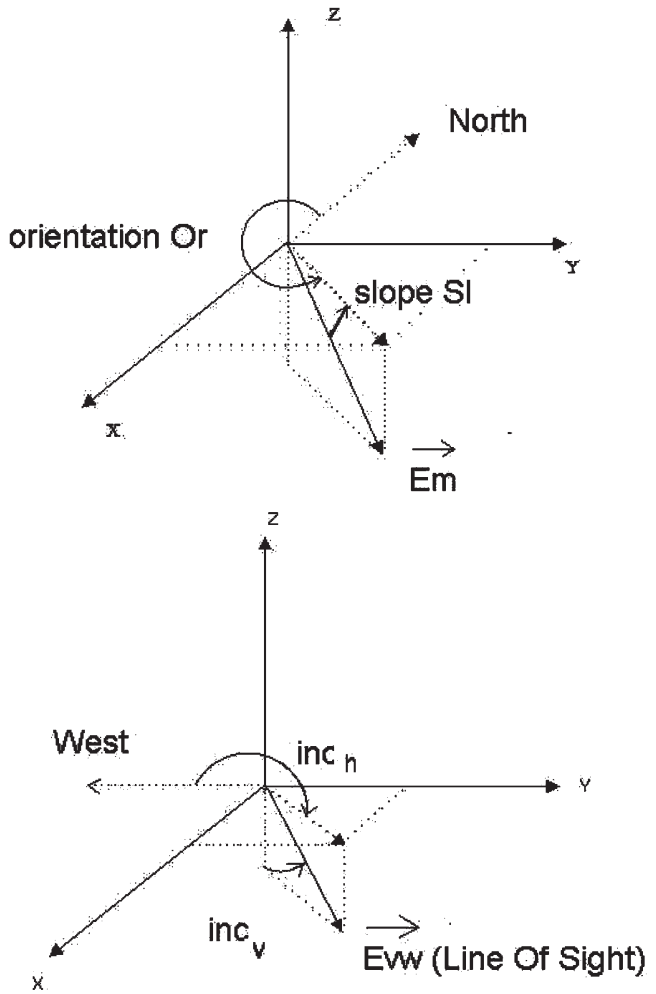

Fig. 13. Glacier surface and SAR LOS orientation angles.

at the current point. The vector representing the satellite LOS is

$$
\vec{E}_{\mathrm{vw}}=\left[\begin{array}{c}
-\sin \left(i n c_{v}\right) \cdot \sin \left(i n c_{h}\right) \\
-\sin \left(i n c_{v}\right) \cdot \cos \left(i n c_{h}\right) \\
-\cos \left(i n c_{v}\right)
\end{array}\right] .
$$

Then, the displacement measured along the $\operatorname{LOS} D_{\mathrm{vw}}$ is computed from the value of the unwrapped phase $\Phi_{u}$, i.e.,

$$
D_{\mathrm{vw}}=\alpha \frac{\Phi_{u}}{2 \pi}
$$

where $\alpha$ is a coefficient containing the geometrical constraints (in the case of ERS satellites $\alpha=28 \mathrm{~mm}$ ). The absolute value of the displacement along the movement direction of the glacier $D_{m}$ is

$$
D_{m}=\frac{D_{\mathrm{vw}}}{\vec{E}_{\mathrm{vw}} \cdot \vec{E}_{m}} .
$$

Finally, the vector of the velocity field on the glacier surface is

$$
\vec{V}_{m}=\frac{D_{m}}{\Delta t} \vec{E}_{m}
$$

where $\Delta t$ is the time interval of the InSAR pair.

The displacement field obtained between the two interferometric SAR acquisitions in the March 1996 descending pass has been converted into quasi-3-D velocity field according to this processing, using either the aerial optical 1995 DTM where it was available or the large-scale DTM. In both cases, the surface gradient has been computed after $200 \times 200 \mathrm{~m}^{2}$ smoothing 
(a)
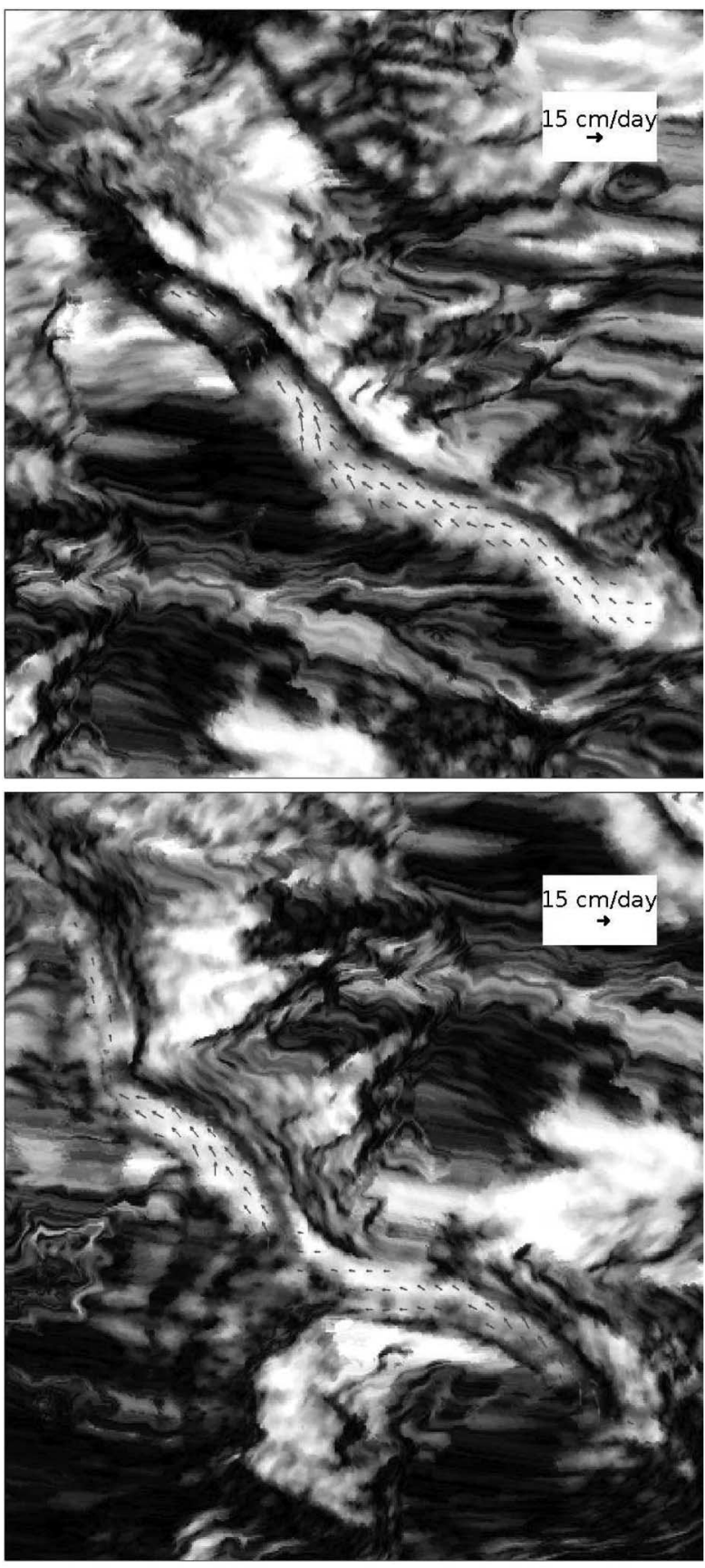

(b)

Fig. 14. Velocity field derived from the ERS-1/2 March 1996 tandem interferogram over the (a) Argentière and (b) Mer de Glace glaciers, which are overlayed on the orthorectified coherence.

in order to avoid taking microrelief into account. The result presented in Fig. 14 illustrates the flow of the Mer de Glace and Argentière glaciers. Vectors are overlayed on the orthorectified coherence, which can be interpreted as a measure of confidence.

\section{B. Comparison With Ground Measurements}

In the following, interferometric and in situ velocity measurements are compared. Three velocity profiles are extracted from the quasi-3-D velocity field described in the previous section from the ERS-1/2 March 1996 tandem interferogram.
They are compared to the annual mean velocity derived from the annual displacement of ablation stakes between 1995 and 1996 over the Argentière and Mer de Glace/Leschaux glaciers. Fig. 15 illustrates the three profiles and associated uncertainty computed, as described in Section V-C. Along the Argentière longitudinal profile [Fig. 15(b)], the InSAR result reveals the velocity evolution: an increasing speed in the accumulation area up to the first crevasse field. The first point of ground measurements (the highest one) has been used to set the phaseunwrapping unknown offset. The InSAR profile keeps close to the following points.

On the Mer de Glace/Leschaux glacier [Fig. 15(b)], the velocity starts with low values in the upper part close to the Mallet glacier, increases quite fast in the Leschaux where the slopes are very steep, and decreases before the junction point with the Mer de Glace. The low velocity observed in this area is probably due to the weak slope and the fluxes, which are too small upstream to sustain a high velocity. Below the confluence, the speed observed on the Mer de Glace is higher than that of the lower part of the Leschaux glacier. Then, it decreases again on the Mer de Glace glacier tongue. The global profile corresponds to the known behavior of these glaciers and to the published results [36], [54].

On the Mer de Glace longitudinal profile, a strong artifact can be observed at the same location as strong slope changes (about $9000 \mathrm{~m}$ from the beginning of the profile). This artifact is due to the conversion of the LOS velocity into 3-D velocity. When the flow direction vector becomes almost perpendicular to the LOS direction, the denominator in (4) becomes close to zero. In this case, the LOS velocity should also be close to zero, but the conversion into 3-D velocity is numerically unstable. This configuration occurs for instance if the slope is oriented toward the radar (this corresponds to the foldover constraint and can be avoided by the use of visibility masks) or when the flow direction is parallel to the azimuth direction (the sensor displacement). In the lower part of the Mer de Glace, the tongue is narrow, and the main slope direction becomes closer to the azimuth direction, which makes the 3-D conversion more sensitive to such artifacts.

\section{Uncertainty Assessment}

A complete performance assessment of the InSAR velocity measurements is rather difficult because of the complex processing chain and the lack of ground truth (only the one-year displacement of a few ablation stakes between the summers of 1995 and 1996 is available). The effect of the different sources of uncertainty is strongly dependent on the available data, the processing strategy, and the characteristics of the glacier [31]. For the results obtained on the studied glacier, two different sources should be distinguished.

1) Uncertainty linked to the data and their processing. In this experiment, the three information sources are the interferometric pair, the DTM, and the in situ measurements used to set the phase-unwrapping offset.

2) Uncertainty linked to the hypotheses used to replace the missing information: in this case, the SPF and the maximum downhill slope assumptions. 
(a)

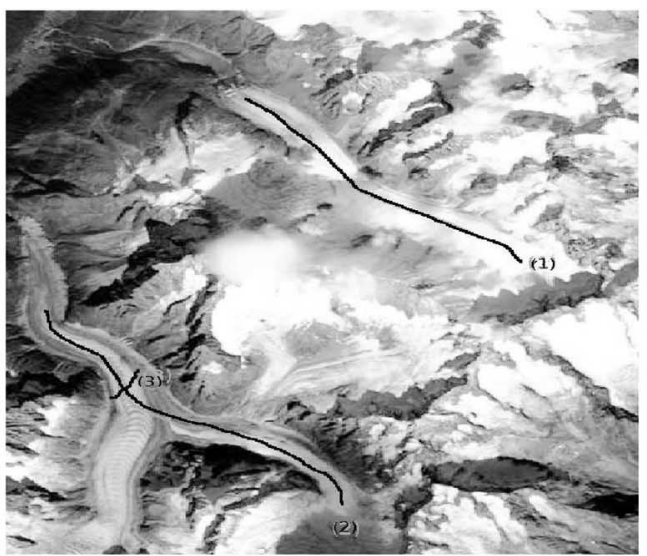

(c)

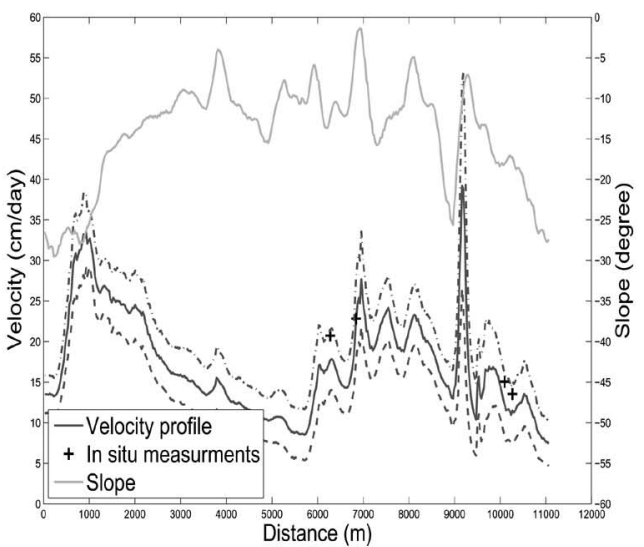

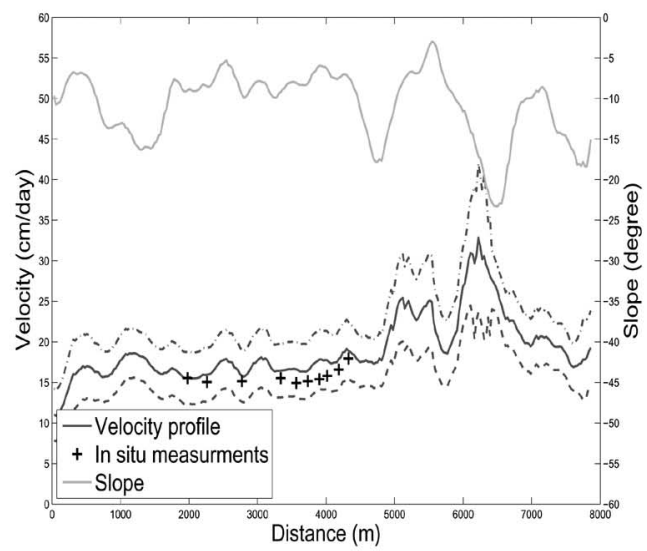

(b)

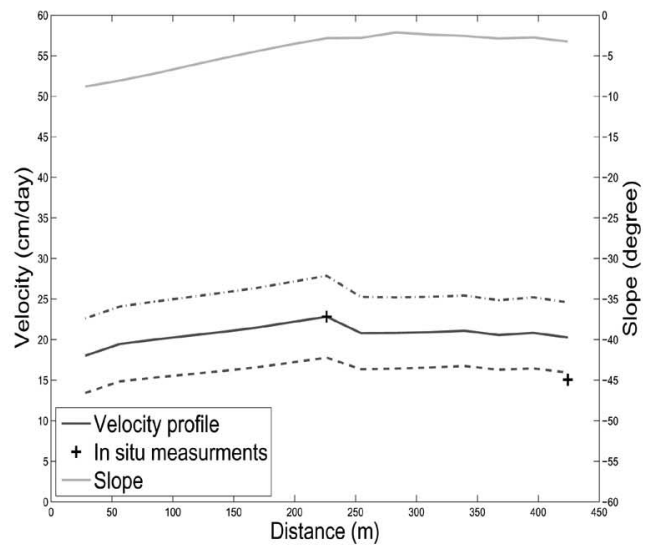

(d)

Fig. 15. ERS-1/2 March 10-11, 1996 velocity profiles. (a) SPOT image and profile location. (b) Longitudinal velocity profile on the Argentière glacier [curve 1 in (a)]. (c) Longitudinal velocity profile on the Leschaux/Mer de Glace glacier [curve 2 in (a)]. (d) Transversal velocity profile on the Mer de Glace glacier [curve 3 in (a)].

1) Data and Processing Uncertainty: The D-InSAR phase measure is affected by three different kinds of uncertainty.

1) The first one comes from the speckle noise, which affects the interferograms, especially in low-coherence areas, and requires appropriate filtering to preserve the small size features of Alpine glaciers. This kind of uncertainty affects each point with random values described by a standard deviation, which can be approximated by the Cramer-Rao lower bound [55], i.e.,

$$
\sigma_{\phi}=\sqrt{\left\langle(\hat{\phi}-\langle\hat{\phi}\rangle)^{2}\right\rangle}=\frac{1}{\sqrt{2 M}} \frac{\sqrt{1-\gamma^{2}}}{\gamma}
$$

where $\gamma$ is the coherence level and $M$ is the number of independent looks averaged to obtain the phase estimate $\hat{\phi}$.

2) The second kind of uncertainty is the presence of fringes due to atmospheric perturbations, remaining orbital or topographic fringes, or hazardous phenomena, which are sometimes encountered in ERS interferograms [24]. Regarding atmospheric perturbations, the small scale of Alpine glaciers and the low winter temperatures should prevent large effect as confirmed by the comparison of different pairs from the same season. Regarding orbital and topographical fringes, this experiment has shown that the use of an accurate DTM and the available precise orbits is sufficient to obtain results that are free of the remaining fringes at the scale of the studied glaciers, even with large baselines. The strong surrounding topography of the Alpine glaciers and the availability of accurate DTMs from airborne photographs help to obtain accurate DTM-SAR registration and fringe removal.

3) The last kind of uncertainty comes from the phaseunwrapping step. Least squares unwrapping errors can be estimated by visual assessment of the remaining fringes. The unknown offset can be obtained by using a singlepoint in situ measurement for a whole connex part of a glacier. The precision depends on how this point is measured (by means of differential GPS, etc.) and how it is temporally related to the SAR measurement (same day/month/year, etc.). The resulting error is the same constant on the whole LOS velocity field.

For the results obtained with the March 10-11, 1996, ERS interferogram, the phase correction and unwrapping error is less than $\pi$ (half a fringe), and the number of looks is approximately $M \simeq 25$ after filtering. Accordingly, the uncertainty that affects the final results can be obtained through the following:

1) computing the LOS uncertainty by adding $\pm \pi / 2$ and $\pm \sigma_{\phi}$ according to the coherence level;

2) applying to this LOS uncertainty the same slopedependent correction as applied to the LOS velocity (4), which brings the final uncertainty to infinity when the main slope direction is perpendicular to the LOS.

The resulting uncertainty is illustrated on the velocity profiles (Fig. 15) and with the corresponding error bar in Fig. 16, which 


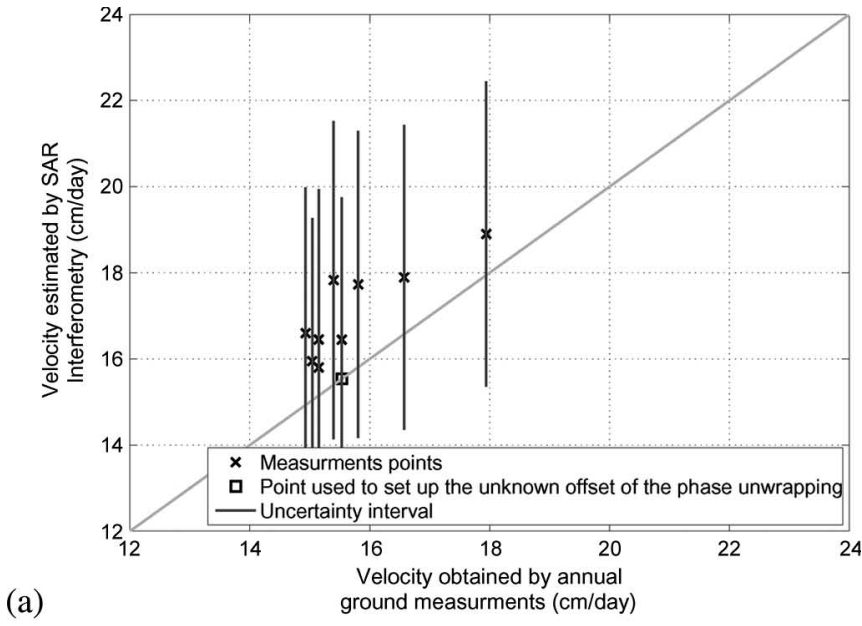

(a)

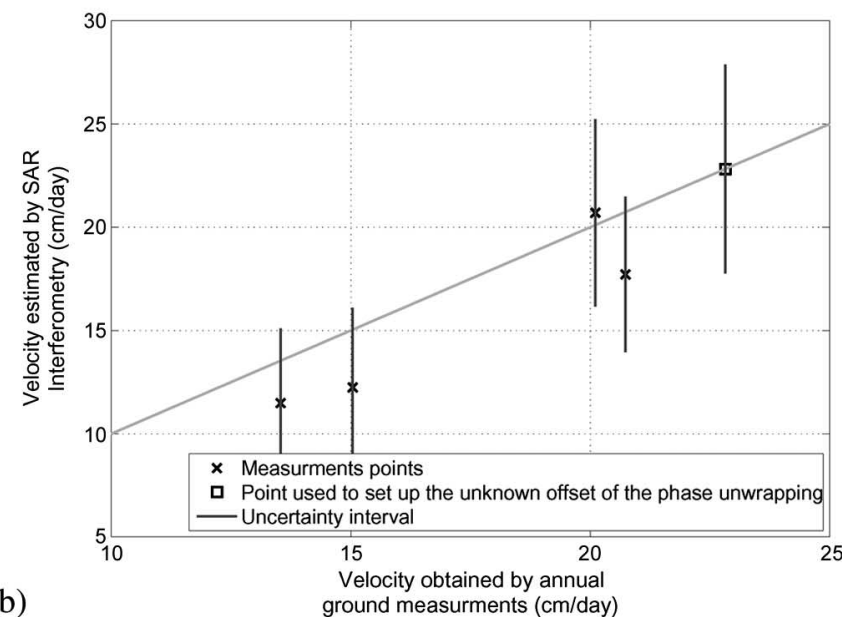

Fig. 16. Comparison between the velocity obtained by SAR interferometry during March 10-11, 1996 and the corresponding annual (August 1995-August 1996) in situ measurement on the (a) Argentière and (b) Mer de Glace glaciers. The rectangle points are those used to set up the phase-unwrapping unknown offsets. The vertical error bars show the D-InSAR velocity uncertainty due to the phase noise, phase corrections, and unwrapping errors, with backprojection in the main slope direction.

presents the InSAR measurement versus the in situ one-year measurement. This comparison does not take the offset error into account. This would yield a translation of the whole set of points. The distance to the diagonal illustrates the agreement of the dense D-InSAR velocity field with the set of in situ measurements.

2) Hypothesis Uncertainty: The hypotheses used to convert InSAR LOS displacement into 3-D velocities is a different source of error, which mainly depends on the studied glaciers and the available complementary information. In this experiment, since only descending measurements are available, the assumptions of SPF and maximum slope direction are used. Uncertainty comes from the slope estimation and the deviation from the hypotheses. Regarding the DTM slope information, a large smoothing (low-pass filter) has to be applied to obtain the main slope direction. This smoothing is large enough to consider that the DTM noise does not affect the slope estimate. The misregistration effect is difficult to assess since it is strongly dependent on the software used for the orthorectification (ROIPAC from JPL in our case) and the topography itself since it creates the features that are necessary for the registration
TABLE III

IN Situ ONE-Year DisPlacement and Local Ablation of Two Transverse Profiles. Comparison of IN SitU AND DTM DERIVED FLOW DIRECTIONS

\begin{tabular}{|c||c|c|c|c|c||c|c|}
\hline \multirow{2}{*}{ Glacier } & \multirow{2}{*}{ Altitude } & \multirow{2}{*}{ No. stakes } & \multirow{2}{*}{ Horizontal disp. } & \multirow{2}{*}{ Vertical disp. } & \multirow{2}{*}{ Ablation } & \multicolumn{2}{|c|}{ Flow direction error } \\
\cline { 7 - 9 } & & & & & Mean & RMS \\
\hline Argentière & $2700 \mathrm{~m}$ & 11 & $56.6 \mathrm{~m}$ & $-5.0 \mathrm{~m}$ & $-0.9 \mathrm{~m}$ & $8.9^{\circ}$ & $17.0^{\circ}$ \\
\hline Mer de Glace & $1900 \mathrm{~m}$ & 4 & $82.4 \mathrm{~m}$ & $-8.9 \mathrm{~m}$ & $-6.7 \mathrm{~m}$ & $8.4^{\circ}$ & $30.7^{\circ}$ \\
\hline
\end{tabular}

in the simulated intensity image. From this experiment, it seems that misregistration does not go over $100 \mathrm{~m}$. Since a larger smoothing $\left(200 \times 200 \mathrm{~m}^{2}\right.$ averaging $)$ has been applied to obtain the main slope and a mask has been used to avoid introducing a glacier border in the smoothing, misregistration should not strongly affect the slope estimate.

The uncertainty due to the SPF assumption is usually small for the fast moving glaciers with strong topography. It mostly affects the vertical component of the velocity, whereas the estimates of the horizontal component should remain relatively unaffected by deviations from the SPF [24]. Errors depend on the submergence/emergence velocity compared to the vertical component of the velocity due to the SPF. For the studied glaciers, it is possible to compare the local mass balance with the one-year displacement of ablation stakes on transverse profiles (cf. Table III). On the Argentière and Mer de Glace glaciers, the ablation represents $20 \%$ up to $75 \%$ of the vertical displacement, depending on the local altitude. Accordingly, the error due to the SPF assumption is not negligible on the vertical component of the velocity. However, in this experiment, the SPF vertical error should be smaller since the InSAR measurements are performed in winter.

A sliding component of the velocity might also affect the assumption that the velocity is in the direction of maximum downward slopes. However, the studied glaciers are quite narrow and long. Even without knowing the basal topography, one can assume that if there is a sliding component (probably small in winter), it will be in the main direction of the valley, which is given by the surrounding mountains and is not very different from the main slope orientation. This assumption has been confirmed by comparing the horizontal direction derived from the DTM with the displacement of ablation stakes. Results reported in Table III show quite good agreement between the DTM directions and in situ measurements on the two glaciers.

\section{Conclusion And Perspective}

In this paper, the results presented on the Mont-Blanc temperate glaciers show the benefits of using both optical and SAR remote sensing data to obtain geophysical measurements on the glacier surfaces. A DTM has been computed using photogrammetric techniques. This high-resolution DTM has been semiautomatically generated, allowing complex and detailed surfaces to be accurately modeled and to generate orthophotos and 3-D representations. SAR interferograms have been computed from the ERS tandem and three-day pairs. SAR processing issues and difficulties due to the geophysical context have been investigated. Displacement fringes have been obtained over several Alpine glaciers in four winter one-day interferograms. The displacement field measured on the radar LOS has been converted into a quasi-3-D velocity field using the DTM under the assumption of surface-parallel motion in the 
direction of the maximum downward slope. A mean velocity provided by in situ measurement at one point has been used to set the unknown offset of the field due to the lack of visibility of the motionless part of the glacier. In this case, the InSAR measurement allows to extend ground-point measurements and provides dense velocity fields, which are consistent with the rest of the available in situ measurements.

These results show the feasibility of using SAR D-InSAR in winter over temperate glaciers and combining this technique with photogrammetry for modeling and monitoring the glacier activity. The spatial resolution of glacier surface velocity fields is increased compared to the sparse terrestrial measurements. Depending on the satellite repeat-pass periodicity, SAR interferometry allows measurements of this field along the cold season. A new SAR observation potential should be investigated with the future TerraSAR-X satellite with a 11-day repeat cycle.

Furthermore, with the higher resolution of recently launched or future SAR satellites (RADARSAT-2, TerraSAR-X, ALOS, and Cosmo-SkyMed), high-quality DTMs become fundamental for D-InSAR applications at different stages in the processing chain: SLC image synthesis, data georeferencing, and computation of the displacement local direction and orientation when a single LOS is available. The next steps in the project described in this paper will focus on the fusion of the obtained measurements and extracted features (lakes, crevasses, ice falls, etc.) to derive higher level information such as hazard factors and risk maps.

\section{ACKNOWLEDGMENT}

The authors would like to thank the ESA for the ERS images provided through Cathegory 1 Projects 1088 and 3525, B. Legresy for the SPOT images, Régie de Gestion des Pays de Savoie (RGD-73/74) for the access to the RIS 73-74 database, and the Laboratory of Glaciology and Geophysics of Environment/Observatoire des Sciences de l'Univers de Grenoble for the in situ measurements. They would also like to thank the anonymous reviewers for providing very precise comments and useful advice on this paper.

\section{REFERENCES}

[1] IPCC, Climate change 2001: The scientific basis, 2001. [Online]. Available: http://www.grida.no/climate/ipcc_tar/wg1

[2] M. B. Dyurgerov, "Mountain and subpolar glaciers show an increase in sensitivity to climate warming and intensification of the water cycle," J. Hydrol., vol. 282, no. 1-4, pp. 164-176, 2003.

[3] S. Richardson and J. Reynolds, "An overview of glacial hazards in the Hymalayas," Quat. Int., vol. 65/66, pp. 31-47, Apr. 2000.

[4] A. Kääb, C. Huggel, L. Fischer, S. Guex, F. Paul, I. Roer, N. Salzmann, S. Schlaefli, K. Schmutz, D. Schneider, T. Strozzi, and Y. Weidmann, "Remote sensing of glacier- and permafrost-related hazards in high mountains: An overview," Nat. Hazards Earth Syst. Sci., vol. 5, no. 4, pp. 527-554, Jul. 2005

[5] R. J. Braithwaite, "Glacier mass balance: The first 50 years of international monitoring," Prog. Phys. Geogr, vol. 26, no. 1, pp. 76-95, Mar. 2002.

[6] A. Kääb, "Combination of SRTM3 and repeat ASTER data for deriving alpine glacier flow velocities in the Bhutan Himalayas," Remote Sens. Environ., vol. 94, no. 4, pp. 463-474, Feb. 2005.

[7] J. Kargel, M. Abrams, M. Bishop, A. Bush, G. Hamilton, H. Jiskoot, A. Kääb, H. Kieffer, E. Lee, F. Paul, F. Rau, B. Raup, J. Shroder, D. Soltesz, D. Stainforth, L. Stearns, and R. Wessels, "Multispectral imag- ing contributions to global land ice measurements from space," Remote Sens. Environ., vol. 99, no. 1/2, pp. 187-219, Nov. 2005.

[8] Régie de gestion des données des pays de savoie. [Online]. Available: http://www.rgd73-74.fr

[9] A. Kääb, "Monitoring high mountain terrain deformation from repeated air- and spaceborne optical data: Examples using digital aerial imagery and ASTER data," ISPRS J. Photogramm. Remote Sens., vol. 57, no. 1/2, pp. 39-52, Nov. 2002.

[10] J. Fox and A. M. Nuttall, "Photogrammetry as a research tool for glaciology," Photogramm. Rec., vol. 15, no. 89, pp. 725-737, 1997.

[11] L. M. Andreassen, H. Elvehoy, and B. Kjollmoen, "Using aerial photography to study glacier changes in Norway," Ann. Glaciol., vol. 34, no. 1 , pp. 343-348, Jan. 2002.

[12] A. K. Gabriel, R. M. Goldstein, and H. A. Zebker, "Mapping small elevation changes over large areas: Differential radar interferometry," J. Geophys. Res., vol. 94, no. B7, pp. 9183-9191, 1989.

[13] D. Massonnet and T. Rabaute, "Radar interferometry, limits and potential," IEEE Trans. Geosci. Remote Sens., vol. 31, no. 2, pp. 455-464, Mar. 1993.

[14] K. E. Mattar, P. W. Vachon, D. Geudtner, A. L. Gray, I. G. Cumming, and M. Brugman, "Validation of alpine glacier velocity measurements using ERS tandem-mission SAR data," IEEE Trans. Geosci. Remote Sens., vol. 36, no. 3, pp. 974-984, May 1998.

[15] B. T. Rabus and D. R. Fatland, "Comparison of SAR-interferometric and surveyed velocities on a mountain glacier: Black rapids glacier," J. Glaciol., vol. 152, no. 46, pp. 119-128, 2000.

[16] R. R. Forster, K. C. Jezek, L. Koenig, and E. Deeb, "Measurement of glacier geophysical properties from InSAR wrapped phase," IEEE Trans. Geosci. Remote Sens., vol. 41, no. 11, pp. 2595-2604, Nov. 2003.

[17] D. Massonnet and K. Feigl, "Radar interferometry and its application to changes in the Earth's surface," Rev. Geophys., vol. 36, no. 4, pp. 441-500, Nov. 1998.

[18] A. I. Sharov, K. Gutjahr, F. Meyer, and M. Schardt, "Methodical alternatives to the glacier motion measurement from differential SAR interferometry," in Proc. Photogramm. Comput. Vis., ISPRS Tech. Commission III Symp., Graz, Austria, 2002, vol. 34, pt. 3A/B, pp. A-324-A-329.

[19] A. Ferretti, C. Prati, and F. Rocca, "Permanent scatterers in SAR interferometry," IEEE Trans. Geosci. Remote Sens., vol. 39, no. 1, pp. 8-20, Jan. 2001.

[20] R. Michel, J. P. Avouac, and J. Taboury, "Measuring ground displacements from SAR amplitude images: Application to the Landers earthquake," Geophys. Res. Lett., vol. 26, no. 7, pp. 875-878, Apr. 1999.

[21] R. Michel and E. Rignot, "Flow of glaciar Moreno, Argentina, from repeat-pass shuttle imaging radar images: A comparison of the phase correlation method with radar interferometry," J. Glaciol., vol. 45, no. 149 , pp. 93-100, 1999.

[22] A. L. Gray, N. Short, K. E. Matter, and K. C. Jezek, "Velocities and ice flux of the Filchner ice shelf and its tributaries determined from speckle tracking interferometry," Can. J. Remote Sens., vol. 27, no. 3, pp. 193 206, 2001.

[23] T. Strozzi, A. Luckman, T. Murray, U. Wegmuller, and C. L. Werner, "Glacier motion estimation using SAR offset-tracking procedures," IEEE Trans. Geosci. Remote Sens., vol. 40, no. 11, pp. 2384-2391, Nov. 2002.

[24] I. Joughin, R. Kwok, and M. A. Fahnestock, "Interferometric estimation of three-dimensional ice-flow using ascending and descending passes," IEEE Trans. Geosci. Remote Sens., vol. 36, no. 1, pp. 25-37, Jan. 1998.

[25] N. Reeh, J. J. Mohr, S. N. Madsen, H. Oerter, and N. S. Gundestrup, "Three-dimensional surface velocities of Storstrommen glacier, Greenland, derived from radar interferometry and ice-sounding radar measurements," J. Glaciol., vol. 49, no. 165, pp. 201-209, 2003.

[26] E. Rignot, R. Forster, and B. Isacks, "Radar interferometric observations of Glacier San Rafael, Chile,” J. Glaciol., vol. 42, no. 141, pp. 279-291, 1996.

[27] T. Strozzi, G. H. Gudmundsson, and U. Wegmüller, "Estimation of the surface displacement of Swiss alpine glaciers using satellite radar interferometry," in Proc. 3rd Workshop Remote Sens. Land, Ice and Snow, Bern, Switzerland, Mar. 11-13, 2002.

[28] P. Sterzai, F. Mancini, C. Corazzato, C. D. Agata, and G. Diolaiuti, "Contribution of SAR interferometry (InSAR) to the study of alpine glaciers. The example of Forni glacier (central Alps, Italy): Preliminary results," in Proc. EGS-AGU-EUG Joint Assembly, Nice, France, Apr. 6-11, 2003.

[29] C. Mätzler and U. Wegmüller, "Dielectric properties of fresh-water ice at microwave frequencies," J. Phys. D, Appl. Phys., vol. 20, no. 12, pp. 1623-1630, Dec. 1987

[30] N. Reeh, S. N. Madsen, and J. J. Mohr, "Combining SAR interferometry and the equation of continuity to estimate the three-dimensional 
glacier surface-velocity vector," J. Glaciol., vol. 45, no. 151, pp. 533-538, 1999.

[31] J. J. Mohr, N. Reeh, and S. N. Madsen, "Accuracy of three-dimensional glacier surface velocities derived from radar interferometry and icesounding radar measurements," J. Glaciol., vol. 49, no. 165, pp. 210-222, 2003.

[32] L. Reynaud, "Etude de la dynamique des séracs du Géant (Massif du Mont Blanc)," Ph.D. dissertation, Univ. Sci. Méd. Grenoble, Grenoble, France, 1973.

[33] G. Bocquet and J. C. Ricq, "Measurement of ice movement in subglacial cavities: A new cavitometer beneath the Glacier d'Argentière (Mt-Blanc, France)," J. Glaciol., vol. 18, no. 78, pp. 137-142, 1977.

[34] C. Vincent, "Influence of climate change over the 20th century on four French glacier mass balances," J. Geophys. Res., vol. 107, no. D19, pp. 43-75, Oct. 2002.

[35] R. Burnet and R. Mura, "Surveillance des glaciers par photographie aérienne," B.T.I., pp. 243-248, 1985. 399/401(B2-Geog.-25).

[36] E. Berthier, H. Vadon, D. Baratoux, Y. Arnaud, C. Vincent, K.L. Feigl, F. Rémy, and B. Legrésy, "Mountain glacier surface motion derived from satellite optical imagery," Remote Sens. Environ., vol. 95, no. 1, pp. 14-28, 2005.

[37] E. Berthier, Y. Arnaud, D. Baratoux, C. Vincent, and F. Rémy, "Recent rapid thinning of the 'Mer de Glace' glacier derived from satellite optical images," Geophys. Res. Lett., vol. 31, no. 17, L17401, 2004.

[38] G. Vasile, E. Trouvé, J.-S. Lee, and V. Buzuloiu, "Intensity-drivenadaptive-neighborhood technique for polarimetric and interferometric sar parameters estimation," IEEE Trans. Geosci. Remote Sens., vol. 44, no. 6, pp. 1609-1621, Jun. 2006.

[39] K. Kraus, Photogrammetrie, 7. Auflage ed, vol. Band 1. Berlin, Germany: Walter de Gruyter Verlag, 2004.

[40] K. Papathanassiou, I. Hajnsek, H. Rott, and T. Nagler, "Polarimetric sar interferometry for snow cover parameter estimation," in Proc. POLinSAR Workshop, 2005, CD-ROM

[41] D. Massonnet, "Producing ground deformation maps automatically: The DIAPASON concept," in Proc. IGARSS, Singapore, 1997, vol. 3, pp. 1338-1340.

[42] H. A. Zebker and R. M. Goldstein, "Topographic mapping from interferometric SAR observations," J. Geophys. Res., vol. 91, no. B5, pp. 49934999, Apr. 1986

[43] P. A. Rosen, S. Hensley, I. R. Joughin, F. K. Li, S. N. Madsen, E. Rodriguez, and R. M. Goldstein, "Synthetic aperture radar interferometry," Proc. IEEE, vol. 88, no. 3, pp. 333-382, Mar. 2000.

[44] P. A. Rosen, S. Hensley, G. Peltzer, and M. Simons, "Updated repeat orbit interferometry package released," Earth Observation Syst. Trans., Amer. Geophys. Union, vol. 85, no. 5, p. 47, 2004. Electronic Supplement. [Online]. Available: http://www.agu.org

[45] J.-M. Nicolas, F. Tupin, G. Vasile, and E. Trouvé, "SAR processing in the temporal domain. Application to direct interferogram generation and mountain glacier monitoring," in Proc. Adv. SAR Workshop, Can. Space Agency, St. Hubert, QC, Canada, Nov. 15-17, 2005, CD-ROM.

[46] R. Hanssen and R. Bamler, "Evaluation of interpolation kernels for SAR interferometry," IEEE Trans. Geosci. Remote Sens., vol. 37, no. 1, pp. 318-321, Jan. 1999.

[47] A. Fischer, H. Rott, and H. Björnsson, "Observation of recent surges of Vatnajkull, Iceland, by means of ERS SAR interferometry," Ann. Glaciol., vol. 37, no. 1, pp. 69-76, Jun. 2003.

[48] G. Vasile, E. Trouvé, M. Ciuc, and V. Buzuloiu, "General adaptive neighborhood technique for improving SAR interferometric coherence estimation," J. Opt. Soc. Amer. A, Opt. Image Sci., vol. 21, no. 8, pp. 1455-1464, Aug. 2004.

[49] H. Tarayre and D. Massonnet, "Atmospheric propagation heterogeneities revealed by ERS-1 interferometry," Geophys. Res. Lett., vol. 23, no. 9, pp. 989-992, 1996.

[50] D. Hantz, "Dynamique et hydrologie du glacier d'Argère," Ph.D. dissertation, CNRS, Lab. Glaciol. Géophys. l'Environ., Saint Martin d'He`res, France, Apr. 1981

[51] R. M. Goldstein, H. A. Zebker, and C. L. Werner, "Satellite radar interferometry: Two-dimensional phase unwrapping," Radio Sci., vol. 23, no. 4, pp. 713-720, Jul. 1988.

[52] D. C. Ghiglia and L. A. Romero, "Robust two-dimensional weighted and unweighted phase unwrapping that uses fast transforms and iterative methods," J. Opt. Soc. Amer. A, Opt. Image Sci., vol. 11, no. 1, pp. 107117, Jan. 1994.

[53] E. Trouvé, J. M. Nicolas, and H. Maître, "Improving phase unwrapping techniques by the use of local frequency," IEEE Trans. Geosci. Remote Sens., vol. 36, no. 6, pp. 1963-1972, Nov. 1998.
[54] L. Lliboutry and L. Reynaud, “'Global dynamics' of a temperate valley glacier, Mer de Glace, and past velocities deduced from Forbes'bands," J. Glaciol., vol. 27, no. 96, pp. 207-226, 1981.

[55] E. Rodriguez and J. M. Martin, "Theory and design of interferometric synthetic aperture radars," Proc. Inst. Electr. Eng.-F, vol. 139, no. 2, pp. 147-159, Apr. 1992.

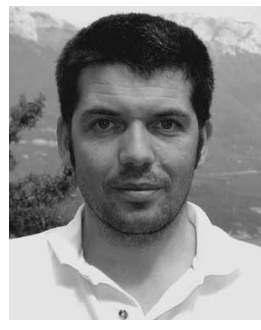

Emmanuel Trouvé (M'99) received the Engineer degree in electrical engineering from the Ecole $\mathrm{Na}-$ tionale Supérieure de Techniques Avancées, Paris, France, in 1990 and the Ph.D. degree in signal and image processing from the Ecole Nationale Supérieure des Télécommunications, Paris, in 1996.

From 1996 to 1998, he was with Thomson Marconi Sonar in underwater acoustic and signal processing. Since September 1998, he has been an Associate Professor of signal processing and computer vision with the Université de Savoie, Polytech'Savoie, Annecy, France, and has been working at the Laboratoire d'Informatique, Systèmes, Traitement de l'Information et de la Connaissance. $\mathrm{He}$ is also currently with the Laboratoire des Images et des Signaux, Institut National Polytechnique de Grenoble, Centre National de la Recherche Scientifique, Saint-Martin-d'Hères, France. He coordinates the French multilaboratory MEGATOR project (Monitoring the Evolution of Alpine Glaciers by Optical and Radar Remote Sensing). His research interests include SAR image processing and data fusion in remote sensing.

Dr. Trouvé is a member of the IEEE Geoscience and Remote Sensing Society Data Fusion Technical Committee.

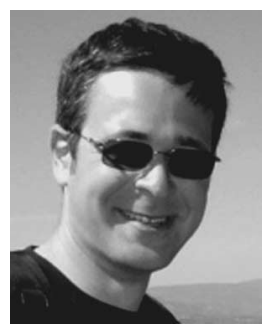

Gabriel Vasile (S'04-M'04) received the Engineer degree in electrical engineering and computer science and the M.S. degree in image, shapes, and artificial intelligence from the University Politehnica of Bucharest, Bucharest, Romania, in 2003 and 2004, respectively. $\mathrm{He}$ is currently working toward the $\mathrm{Ph} . \mathrm{D}$. degree at the University Politehnica of Bucharest and the University of Savoie, Polytech'Savoie, Annecy, France. Since 2004, he has been working on his Ph.D. dissertation on SAR multivariate signal processing with joint supervision from both the University Politehnica of Bucharest and the University of Savoie, Polytech'Savoie, in the framework of the French multilaboratory MEGATOR Project.

From 2001 to 2003, he was an Engineering Assistant with the Center of Microsystems and Microstructures for Environmental Monitoring and Biomedical Applications, National Institute for Research and Development in Micro and Nanotechnologies, Romania. He is currently with the Laboratoire d'Informatique, Systèmes, Traitement de l'Information et de la Connaissance, Université de Savoie and also with the Laboratoire des Images et des Signaux, Institut National Polytechnique de Grenoble, Centre National de la Recherche Scientifique, Saint-Martin-d'Hères, France. His research interests are signal and image processing, polarimetric and interferometric SAR applications, and glacier monitoring.

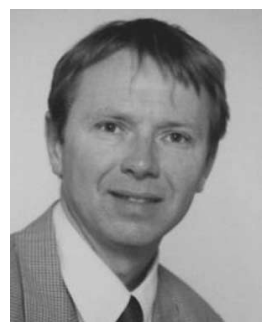

Michel Gay received the Engineer degree in electrical engineering from the Institut des Sciences de l'Ingénieur de Montpellier, Montpellier, France, in 1987 and the Ph.D. degree in physics from the University Joseph Fourier, Grenoble, France, in 1999.

From 1988 to 2003, he was with Cemagref Grenoble, Grenoble, where he worked on electrical engineering for environmental applications. Since 2003, he has been a Research Engineer with the Laboratoire des Images et des Signaux, Institut National Polytechnique de Grenoble, Centre National de la Recherche Scientifique, Saint-Martin-d'Hères, France. His research interests include remote sensing, image processing, and survey of Alpine glaciers. 


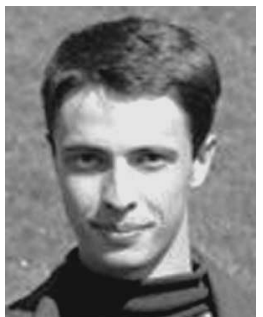

Lionel Bombrun (S'06) received the Engineer degree in electrical engineering and the M.S. degree in signal, image, speech, and telecommunications from the Grenoble National Polytechnic Institute (INPG), Grenoble, France, in 2005. He is currently working toward the Ph.D. degree at the Grenoble Image Parole Signal et Automatique Laboratory, INPG, Centre National de la Recherche Scientifique, SaintMartin-d'Hères, France. Since 2005, he has been working on his Ph.D. dissertation on the development of SAR signal processing at the Laboratoire des Images et des Signaux, INPG, Centre National de la Recherche Scientifique, in the framework of the French multilaboratory MEGATOR Project.

His research interests include SAR polarimetry and interferometry, and glacier monitoring.

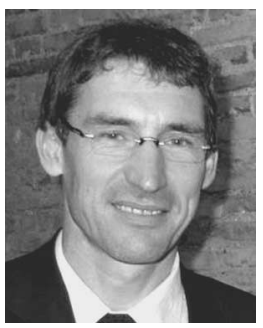

Pierre Grussenmeyer received the Engineer degree in geodetic surveying and topography from Ecole Nationale Supérieure des Arts et Industries de Strasbourg (ENSAIS) [currently Institut National des Sciences Appliquees (INSA) de Strasbourg (a Graduate School of Science and Technology)], Strasbourg, France, in 1984 and the Ph.D. degree in photogrammetry from the University of Strasbourg I (in relationship with the Institut Geographique National, Paris, France), Strasbourg, in 1994.

From 1988 to 2004, he was an Associate Professor with ENSAIS. Since 2004, he has been a Professor with INSA Strasbourg and the Head of the Equipe Photogrammétrie et Géomatique, Modèles et Simulations pour l'Architecture, l'Urbanisme et le Paysage-Photogrammetrie Architechturale et Geomatique UMR 694. His current research interests include close-range photogrammetry, architectural photogrammetry and lasergrammetry, visual and virtual models, and cultural heritage documentation.

Prof. Grussenmeyer has been a member of the International Society for Photogrammetry and Remote Sensing since 1996 and the Treasurer and a Member of the board of the International Committee for Architectural Photogrammetry since 1999. He is also a Vice President of the Association Française de Topographie.

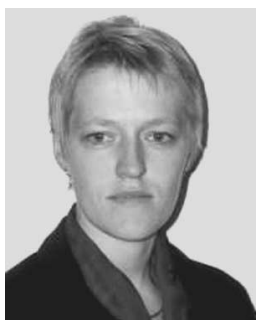

Tania Landes received the Engineer degree in geodetic surveying and topography in 1995 from ENSAIS [currently Institut National des Sciences Appliquees (INSA) de Strasbourg (Graduate School of Science and Technology)], Strasbourg, France, and the $\mathrm{Ph} . \mathrm{D}$. degree in radar remote sensing from the University of Karlsruhe, Karlsruhe, Germany, in 2000 .

Since 2006, she has been an Associate Professor with ENSAIS. She is currently with the Equipe Photogrammétrie et Géomatique, Modèles et Simulations pour l'Architecture, l'Urbanisme et le Paysage-Photogrammetrie Architechturale et Geomatique UMR 694, INSA. Her current research interests include remote sensing and lasergrammetry.

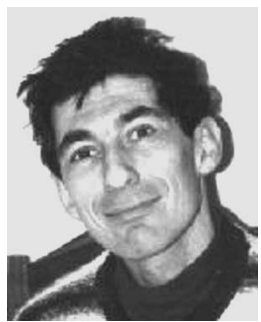

Jean-Marie Nicolas received the M.S. degree from the Ecole Normale Superieure de Saint Cloud, Lyon, France, in 1979 and the $\mathrm{Ph} . \mathrm{D}$. degree in physics from the University of Paris XI, Paris, France, in 1982.

He was a Research Scientist with the Laboratoire d'Electronique Philips in medical imaging and was then with Thomson CSF, working in signal and image processing. He is currently with the Département TSI, Ecole Nationale Superieure des Telecommunications, Paris, as a Professor. His research interests include radar imaging.

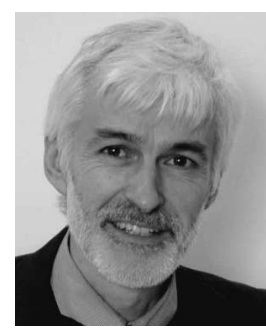

Philippe Bolon (M'94) was born in 1956. He received the Engineer degree in electrical engineering and the Ph.D. degree in signal processing from the National Polytechnic Institute of Grenoble (INPG), Grenoble, France, in 1978 and 1981, respectively.

From 1984 to 1994, he was an Associate Professor with the Université de Savoie, Polytech'Savoie, Annecy, France. He has been Professor with the Université de Savoie, Polytech'Savoie since September 1994 and the Head of the Laboratoire d'Informatique, Systèmes, Traitement de l'Information et de la Connaissance since 2002. Since 1996, he has been a Member of the steering committee of the French national research group in Signal and Image Processing (GdR ISIS). His current research interests include information fusion, nonlinear image processing, image segmentation, and image analysis.

Dr. Bolon is a member of the European Association for Signal Processing. He was the Chairman or a Cochairman of the Scientific Committee of the International Conference on Quality Control by Artificial Vision (QCAV) in 1997, 1998, 1999, 2001, and 2003.

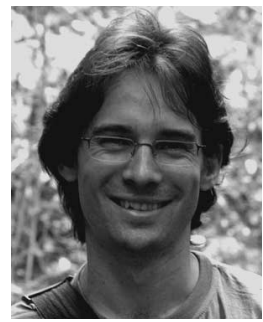

Ivan Petillot received the Engineer degree in electrical engineering and computer sciences and the M.S. degree in image, information, and hypermedia from the Institut de Recherche en Informatique de Toulouse, Toulouse, France, in 2005. He is currently working toward the Ph.D. degree at the Laboratoire d'Informatique, Systèmes, Traitement de l'Information et de la Connaissance, Université de Savoie, Polytech'Savoie, Annecy, France. Since 2005, he has been working on his Ph.D. dissertation on the information fusion systems for remote sensing at the University of Savoie, in the framework of the MEGATOR Project.

His research interests include information fusion, risk assessment, and glacier monitoring.

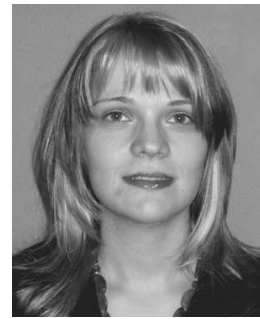

Andreea Julea received the Engineer degree in electrical engineering and computer science and the M.S. degree in image processing and artificial intelligence from the University Politehnica of Bucharest, Bucharest, Romania, in 2005 and 2006, respectively. She is currently working toward the Ph.D. degree at the Laboratoire d'Informatique, Systèmes, Traitement de l'Information et de la Connaissance, Université de Savoie, Polytech'Savoie, Annecy, France. Since 2006, she has been working on her Ph.D. dissertation on data mining in remote sensing applications with joint supervision from the University Politehnica of Bucharest and University of Savoie.

Since 2006, she has been with the Space Sciences Institute, Bucharest. Her research interests are data mining, image processing, and remote sensing.

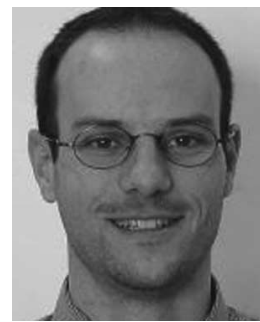

Lionel Valet received the M.S. degree from the Ecole Superieur d'Ingenieur d'Annecy, University of Savoie, Annecy, France, in 1998 and the Ph.D. degree in signal and image processing from the University of Savoie, in 2001.

$\mathrm{He}$ is currently an Associate Professor in computer science with the Laboratoire d'Informatique, Systèmes, Traitement de l'Information et de la Connaissance, Université de Savoie, Polytech'Savoie. His research interests include information fusion system conception with applications to image analysis. 


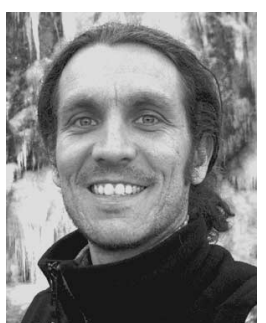

Jocelyn Chanussot (M'04-SM'04) received the Engineer degree in electrical engineering from the Institut National Polytechnique de Grenoble (INPG), Grenoble, France, in 1995 and the Ph.D. degree from Savoie University, Annecy, France, in 1998.

In 1999, he was with the Geography Imagery Perception Laboratory for the Delegation Generale de l'Armement (French National Defence Department). Since 1999, he has been an Associate Professor of signal and image processing with INPG, Centre National de la Recherche Scientifique, Saint-Martind'Hères, France, and has been working at the Laboratoire des Images et des Signaux. His research interests include statistical modeling, multicomponent image processing, nonlinear filtering, remote sensing, and data fusion. He is an Associate Editor for Pattern Recognition (2006-2008).

Dr. Chanussot is an Associate Editor of the IEEE Geoscience AND Remote Sensing Letters (since 2005). He is a Cochair of the IEEE Geoscience and Remote Sensing Society Data Fusion Technical Committee (2005-2007) and a member of the Machine Learning for Signal Processing Technical Committee of the IEEE Signal Processing Society (2006-2008). He serves as a regular reviewer for various conferences (e.g., IEEE ICASSP, IEEE ICIP, ACIVS).

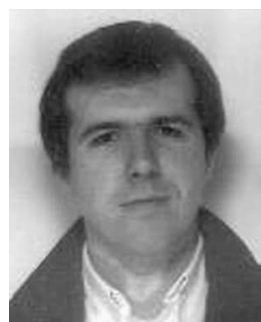

Mathieu Koehl received the Engineer degree in geodetic surveying and topography from ENSAIS [currently Institut National des Sciences Appliquees (INSA) de Strasbourg (a Graduate School of Science and Technology)], Strasbourg, France, in 1990 and the $\mathrm{Ph} . \mathrm{D}$. degree in geomatics from the University of Strasbourg I, Strasbourg (in relationship with the Technische Universitat Vienna, Vienna, Austria), in 1999.

Since 1994, he has been an Associate Professor with the Equipe Photogrammétrie et Géomatique, Modèles et Simulations pour l'Architecture, l'Urbanisme et le PaysagePhotogrammetrie Architechturale et Geomatique UMR 694, INSA de Strasbourg. His current research interests include 3-D modeling, 3-D GIS, and WebGIS. 